\title{
Combination of curcumin and ginkgolide $B$ inhibits cystogenesis by regulating multiple signaling pathways
}

\author{
YOUSONG $\mathrm{LI}^{1 *}, \mathrm{JINSHENG} \mathrm{GAO}^{2 *}, \mathrm{XI}$ YANG $^{3 *}, \mathrm{TAO} \mathrm{LI}^{2}, \mathrm{BAOXUE} \mathrm{YANG}^{4}$ and AIXINGZI AILI ${ }^{5}$ \\ ${ }^{1}$ Department of Traditional Chinese Medicine, Shanxi Bethune Hospital, Taiyuan, Shanxi 030032; \\ ${ }^{2}$ Ping An Healthcare and Technology Company Limited ('Ping an'), Shanghai 200120; \\ ${ }^{3}$ Cancer Institute, Longhua Hospital, Shanghai University of Traditional Chinese Medicine, Shanghai 200032; \\ ${ }^{4}$ Department of Pharmacology, School of Basic Medical Sciences, Peking University, Beijing 100083 ; ${ }^{5}$ Department of \\ Gynecology, Shanghai First Maternity and Infant Hospital, Tongji University School of Medicine, Shanghai 201204, P.R. China
}

Received June 10, 2020; Accepted November 20, 2020

\section{DOI: $10.3892 / \mathrm{mmr} .2021 .11834$}

\begin{abstract}
Autosomal dominant polycystic kidney disease (ADPKD), a common disease with a high incidence ratio of between 1/400 and 1/1,000 individuals, often results in kidney failure and even mortality. However, there are relatively few effective treatments available, and treatment is limited to lifelong hemodialysis or kidney transplant. Our previous studies have reported that curcumin (Cur) and ginkgolide B (GB) inhibited cystogenesis by regulating the Ras/ERK MAPK signaling pathway. In the present study, it was hypothesized that Cur and GB may have a synergistic effect on the inhibition of cystogenesis, and their synergistic effect may be the result of regulation of multiple signaling pathways. To assess this hypothesis, an in vitro Madin-Darby canine kidney (MDCK) cyst model and an in vivo kidney-specific polycystin 1 transient receptor potential channel interacting $(P k d l)$ knockout mouse model were established to observe the effects of the combination of Cur and GB. The cysts exposed to Cur, GB and Cur combined with GB became small thick-walled cysts, small thin-walled cysts and round shaped cell colonies, respectively. The combination of Cur and GB was more effective compared with either treatment alone in inhibiting cystogenesis.
\end{abstract}

Correspondence to: Dr Jinsheng Gao, Ping An Healthcare and Technology Company Limited ('Ping an'), Building 4, 88 Shengrong Road, Pudong New Area, Shanghai 200120, P.R. China

E-mail: gjs1121@126.com

Professor Aixingzi Aili, Department of Gynecology, Shanghai First Maternity and Infant Hospital, Tongji University School of Medicine, 2699 Gaoke West Road, Pudong New Area, Shanghai 201204, P.R. China

E-mail: axzal41@126.com

*Contributed equally

Key words: curcumin, ginkgolide B, polycystin 1 transient receptor potential channel interacting knockout mice, autosomal dominant polycystic kidney disease, renal cyst, signaling pathway
Additionally, to the best of our knowledge, the present study was the first to demonstrate the synergistic effect of Cur and GB on the inhibition of cystogenesis in $P k d l$ knockout mice. Cur may have mediated its anti-cyst effects by blocking EGFR/ERK1/2, JNK and PI3K/mTOR signaling pathways, while GB may have inhibited cystogenesis via the downregulation of the EGFR/ERK1/2, JNK and p38 signaling pathways. These results provide a proof-of-concept for application of the combination of Cur and GB in inhibiting cystogenesis in ADPKD.

\section{Introduction}

Autosomal dominant polycystic kidney disease (ADPKD), one of the most common diseases of the kidney, has a high incidence rate of $1 / 400$ to $1 / 1,000$ individuals (1), and is characterized by several unregulated cysts of different sizes in the kidney, and often progresses to kidney failure (2). The disease is primarily caused by mutations in polycystin 1 transient receptor potential channel interacting $(P k d 1 ; 85 \%)$ and $P k d 2$ (15\%), which encode the proteins polycystin-1 (PC1) and polycystin-2 (PC2), respectively $(3,4)$. Previous studies have reported that mutant PC1 and PC2 decrease intracellular $\mathrm{Ca}^{2+}$ levels and increase intracellular cAMP levels (5-7). Increased intracellular cAMP stimulates protein kinase $\mathrm{A}$, which in turn promotes abnormal proliferation of cyst epithelial cells and excessive secretion of cyst fluid $(6,8)$. There are multiple signaling pathways associated with abnormal proliferation of cyst epithelial cells, such as the Ras/MAPK pathway, mTOR pathway and Wnt pathway (9-11). Signaling pathways associated with excessive secretion of cyst fluid include those that increase the activities of cystic fibrosis transmembrane conductance regulator (CFTR), $\mathrm{Na}^{+}-\mathrm{K}^{+}$-ATPase and aquaporin 2 (12). Other signaling factors include TGF- $\beta / \operatorname{Smad} 2 / 3$ (13) and integrin-linked kinase (14), and are associated with the pathological progression of fibrosis throughout the course of ADPKD.

Except for lifelong hemodialysis or kidney transplantation, treatments for ADPKD include decreasing intracellular cAMP levels, prevention of abnormal cells proliferation and inhibition of cyst fluid excessive secretion (15). Somatostatin, and its analogue octreotide, inhibit cyst development by decreasing intracellular cAMP levels in the kidney and liver 
in patients with ADPKD (16). Our previous studies revealed that curcumin (Cur) (15) and ginkgolide B (GB) (17) reduced renal cyst cell proliferation by downregulating the activity of the Ras/ERK1/2 signaling pathway. Small-molecule CFTR inhibitors decrease cyst fluid secretion in PKD by inhibiting the function of CFTR, which in turn stimulates chloride secretion, and thus cystic fluid secretion (12). Other treatments that decrease cyst growth in ADPKD include tolvaptan $(18,19)$, src inhibitors (20), Wnt inhibitors (21), mTOR inhibitors (22), pioglitazone $(23,24)$, triptolide $(25)$, Ganoderma triterpenes (26) and Quercetin (27). Tolvaptan has been approved for the treatment of ADPKD in Europe and other countries throughout the world (28). However, the majority of experimental treatments for ADPKD require further study before they can be approved clinically.

Cur is a natural compound isolated from the Traditional Chinese Medicine Curcuma longa L (29). Several studies have shown that Cur exhibits notable anticancer, anti-inflammatory (30) and anti-oxidant effects, as well as other beneficial properties $(31,32)$. Our previous study revealed that Cur inhibited cyst development in vitro (15). GB is a natural product isolated from the Chinese herbal medicine Ginkgo biloba L (33), and has several beneficial biological effects, including antiplatelet, anti-inflammatory, antioxidant and neuroprotective activities $(34,35)$. The inhibitory effect of GB on cyst formation was also reported in our previous study, both in in vitro and in vivo models (17). Considering these inhibitory effects of Cur and GB on cyst formation, it was hypothesized that Cur and GB may exhibit a synergistic effect on the inhibition of cystogenesis, and this synergistic effect may result from the regulation of multiple signaling pathways. To assess this hypothesis, in the present study, an in vitro Madin-Darby canine kidney (MDCK) cyst model and an in vivo kidney-specific $P k d l$ knockout mouse model were used to observe the effects of Cur combined with GB.

\section{Materials and methods}

Materials. Cur (Sigma-Aldrich; Merck KGaA; cat. no. C1386), GB (Sigma-Aldrich; Merck KGaA; cat. no. G6910) and Forskolin (FSK; Sigma-Aldrich; Merck KGaA; cat. no. F6886) were each dissolved in $100 \%$ DMSO to prepare a $100 \mathrm{mM}$ stock solution and were stored at- $20^{\circ} \mathrm{C}$.

Anti-phospho-(p-)EGFR (cat. no. sc-57542), anti-EGFR (cat. no. sc-373746), anti-p-human epidermal growth factor receptor 2 (anti-p-Cerb-B2; cat. no. sc-81507), anti-Cerb-B2 (cat. no. sc-33684), anti-H-Ras (cat. no. sc-35), anti-B-Raf (cat. no. sc-5284), anti-Raf-1 (cat. no. sc-7267), anti-p-MEK-1/2 (cat.no.sc-81503), anti-MEK-1/2 (cat.no.sc-81504), anti-p-ERK (cat.no.sc-7383), anti-ERK-1/2 (cat. no. sc-514302), anti-p-JNK (cat. no. sc-6254), anti-JNK (cat. no. sc-7345), anti-p-activator of S phase kinase (ASK; cat. no. sc-166967), anti-ASK1 (cat. no. sc-5294), anti-p-p38 $\alpha$ (cat. no. sc-7973), anti-p38 $\alpha / \beta$ (cat. no. sc-7972) and anti-Actin (cat. no. sc-8432) were purchased from Santa Cruz Biotechnology, Inc. Anti-p-PI3K (cat. no. 4228), anti-PI3K (cat. no. 4292), anti-p-AKT (cat. no. 4060), anti-AKT (cat. no. 4691), anti-p-mTOR (cat. no. 2971), anti-mTOR (cat. no. 2972), anti-p-eukaryotic translation initiation factor $4 \mathrm{E}$ binding protein 1 (anti-p-4E-BP1; cat. no. 2855), anti-4E-BP1 (cat. no. 9452),
anti-p-p70S6 kinase (anti-p-p70S6k; cat. no. 9208), anti-p70S6k (cat. no. 9202), anti-p-mitogen-activated protein kinase kinase kinase 7 (anti-p-MAP3K7; cat. no. 9339), anti-MAP3K7 (cat. no. 4505), anti-p-mitogen-activated protein kinase kinase 3/6 (anti-p-MKK3/6; cat. no. 9231), anti-MKK3 (cat. no. 5674), anti-p-MKK4 (cat. no. 9155) and anti-MKK4 (cat. no. 9152) were purchased from Cell Signaling Technology, Inc. Horseradish peroxidase (HRP) conjugated-goat anti-mouse IgG $(\mathrm{H}+\mathrm{L})$ (cat. no. AP308P) and unconjugated goat anti-rabbit IgG (cat. no. AP132) were purchased from Sigma-Aldrich (Merck KGaA).

MDCK cyst model. Type I MDCK cells (American Type Culture Collection; cat. no. CCL-34) were cultured at $37^{\circ} \mathrm{C}$ in a humidified incubator with $5 \% \mathrm{CO}_{2}$ and $95 \%$ air in a $1: 1$ mixture of DMEM (Mediatech, Inc.; cat. no. 07119003) and Ham's F-12 nutrient medium (Mediatech, Inc.; cat. no. 30218008) supplemented with 10\% FBS (Hyclone; Cytiva), $100 \mathrm{U} / \mathrm{ml}$ penicillin and $100 \mu \mathrm{g} / \mathrm{ml}$ streptomycin. MDCK cells ( 400) were suspended in $0.4 \mathrm{ml}$ ice-cold Minimum Essential Medium (Mediatech, Inc.; cat. no. 12619015) containing $2.9 \mathrm{mg} / \mathrm{ml}$ collagen (PureCol; Inamed Biomaterials), $10 \mathrm{mM}$ HEPES, $27 \mathrm{mM} \mathrm{NaHCO}, 100 \mathrm{U} / \mathrm{ml}$ penicillin and $100 \mathrm{mg} / \mathrm{ml}$ streptomycin ( $\mathrm{pH}$ 7.4). The MDCK cell suspension was cultured in 24-well plates for $90 \mathrm{~min}$, after which, the cells were treated at $37^{\circ} \mathrm{C}$ with the different compound combinations as follows: $10 \mu \mathrm{M}$ FSK; $0,0.4,2$ or $10 \mu \mathrm{M}$ Cur; and $0,0.125,0.5$ or $2 \mu \mathrm{M}$ GB for 4 days. Medium containing FSK and Cur or GB was changed every $12 \mathrm{~h}$. After cells were cultured for 4 days, MDCK cysts formed in the continuous presence of $10 \mu \mathrm{M}$ FSK at $37^{\circ} \mathrm{C}$ for 4 days.

To evaluate the inhibitory effect of Cur and GB on cyst formation in the MDCK cyst model, different combinations of $\operatorname{Cur}(0,0.4,2$ or $10 \mu \mathrm{M})$ and $\mathrm{GB}(0,0.125,0.5$ or $2 \mu \mathrm{M})$ were added to the culture medium containing $10 \mu \mathrm{M}$ FSK at $37^{\circ} \mathrm{C}$ from day 0 to day 5 . Medium containing FSK and the combination of Cur and GB was changed every $12 \mathrm{~h}$ for 6 days. Cysts with a diameter $>50 \mu \mathrm{m}$ and non-cyst cell colonies were counted under an Olympus confocal microscopy (Olympus Corporation) on the 6th day (magnification, x200). The MDCK cyst formation inhibitory rate was calculated as follows: [(number of cysts in MDCK cyst model without treatment-number of cysts in MDCK cyst model with treatment)/number of cysts in MDCK cyst model without treatment] x100\%.

To determine inhibition of cyst growth mediated by Cur and GB, different dose combinations of Cur $(0,0.4,2$ or $10 \mu \mathrm{M})$ and $\mathrm{GB}(0,0.125,0.5$ or $2 \mu \mathrm{M})$ were added to the culture medium containing $10 \mu \mathrm{M} \mathrm{FSK}$ at $37^{\circ} \mathrm{C}$ from day 4 to day 9 . Medium containing FSK and the combination of Cur and GB was changed every $12 \mathrm{~h}$ for 6 days. Cysts were observed on days 4, 6, 8 and 10 using an in situ tracking method (identified by markings on plates) (17). To evaluate growth, cysts with diameters $>50 \mu \mathrm{m}$ were measured on days $4,6,8$ and 10 using Image-Pro Plus version 6.0 (Media Cybernetics, Inc.). In total, $\geq 10$ cysts/well and 3 wells/group were measured for each condition.

Pkdl flox/- Ksp-Cre mouse of ADPKD. Pkd1 flox mice and kidney-specific Cre (Ksp-Cre) transgenic mice were established 
as described previously, and were housed at $22 \pm 3^{\circ} \mathrm{C}$ under $50 \pm 5 \%$ relative humidity with a $12 \mathrm{~h}$ light/dark cycle with food and water available on demand in the laboratory (17). There was $-15 \mathrm{~Pa}$ atmosphere pressure difference between inside and outside laboratory. The animal use protocol has been reviewed and approved by the Institutional Animal Care and Use Committee of Shanxi Bethune Hospital. Pkd1 Flox/$K s p$-Cre mice were used to evaluate the effects of Cur and GB on cyst inhibition. The $P k d 1^{\text {Flox/- }}$; Ksp-Cre homozygous mice generally die within 15 days of birth (27). Thus, treatments were performed only up until postnatal day 10 . Neonatal mice (postnatal day 0) were genotyped using genomic PCR. A total of 96 homozygous mice (half male and half female; age, 1 day; weight, $3.07 \pm 0.66 \mathrm{~g}$ ) were randomly divided into three treatment groups (Cur group, GB group, Cur and GB combination group) and PKD mice group ( $2 \mu \mathrm{l} \mathrm{x}$ body weight $\mathrm{DMSO}+$ saline, $0.05 \mathrm{ml} / \mathrm{injection})$. A total of six heterozygous mice (half male and half female; age, 1 day; weight, $2.75 \pm 0.93 \mathrm{~g}$ ) were used as the wild-type (WT) mice group. Each group had six mice to ensure the reliability of statistical analysis. The homozygous mice are characterized by rapidly progressive disease, providing only a very small window for treatment of the neonates (13). GB $(0,20,40$ or $80 \mathrm{mg} / \mathrm{kg})$ and Cur $(0,80,160$ and $320 \mathrm{mg} / \mathrm{kg})$ were injected subcutaneously in the back of neonatal mice once a day from days 1-10 using a 1-ml insulin syringe. The mice were weighed on day 11, and were anesthetized by intraperitoneal injection of pentobarbital sodium $(50 \mathrm{mg} / \mathrm{kg})$. Then, mice were sacrificed by cervical dislocation and decapitated. The kidney, liver and spleen tissues were removed and weighed, and stored at $4^{\circ} \mathrm{C}$ in $10 \%$ formalin solutions. The ratio of kidney weight to body weight was calculated and analyzed. The kidney cysts were evaluated by the percentage of cyst area to kidney area. The effects of Cur and GB on liver and spleen were observed by measuring liver weight/body weight and spleen weight/body weight. Blood samples $(0.3 \mathrm{ml})$ were centrifuged in heparinized Microtainer tubes at $3,000 \mathrm{x} \mathrm{g}$ for $10 \mathrm{~min}$ at $4{ }^{\circ} \mathrm{C}$. Urea concentration was tested using urea assay kit (Bioassay Systems). The blood urea nitrogen (BUN) (mg/dl) was calculated as 2.14 divided by urea (mg/dl).

Immunohistochemistry. Kidney tissue samples were fixed in $4 \%$ formaldehyde at $\mathrm{pH} 7.4$ and $4^{\circ} \mathrm{C}$ for $48 \mathrm{~h}$, dehydrated, embedded in paraffin, and stained with hematoxylin for $5 \mathrm{~min}$ and eosin for $3 \mathrm{~min}$ at room temperature. To detect tissue localization and expression of EGFR and Cerb-B2, tissues were sectioned at $5-\mu \mathrm{m}$ in thickness and stained as follows. The section was blocked by $1 \%$ hydrogen peroxide in methanol for $10 \mathrm{~min}$ at $37^{\circ} \mathrm{C}$. Antigens were retrieved by microwaving in $10 \mathrm{mM}$ citrate buffer $(\mathrm{pH} 6.0)$ at $95^{\circ} \mathrm{C}$ for $10 \mathrm{~min}$. Slides were blocked with 5\% normal goat serum (Abcam; cat. no. ab7481) at room temperature for $20 \mathrm{~min}$. Then, the sections were incubated in a humidified chamber at $4^{\circ} \mathrm{C}$ overnight with one of the primary antibodies, including anti-EGFR (1:100) and anti-Cerb-B2 (1:100). The slides were washed three times with PBS, incubated at $37^{\circ} \mathrm{C}$ for 20 min with biotinylated second antibody (1:200), and labeled for $20 \mathrm{~min}$ with HRP. Peroxidase activity was visualized using a DAB concentrated kit (Bioswamp Life Science Lab; cat. no. PAB180021). Samples were observed under an Olympus confocal microscopy
(Olympus Corporation) at x400 magnification by two experienced pathologists blinded to the conditions. Positive staining was quantitatively analyzed using Image-Pro-Plus (version 6.0; Media Cybernetics, Inc.; https://www.mediacy.com/), and the average optical density was the result of cumulative optical density divided by total area. These results were statistically analyzed.

Western blotting. The kidney tissues were homogenized using a homogenizer (FLUKO; FA25) at $8,000 \mathrm{x}$ g for $2 \mathrm{~min}$ at $4^{\circ} \mathrm{C}$, incubated on ice for $20 \mathrm{~min}$ and lysed using an ultrasonic cell crusher (Shanghai Hannuo Instrument Co., Ltd.; http://www. hanuo.com.cn/; HN-250M) for $3 \mathrm{~min}$ at $4^{\circ} \mathrm{C}$ in a protein lysis buffer $(10 \mathrm{mM}$ triethanolamine at $\mathrm{pH} 7.6$ and $250 \mathrm{mM}$ sucrose) and protease inhibitor cocktail (1 mM PMSF, $20 \mathrm{mM}$ $\mathrm{NaF}$ and $1 \mathrm{mM} \mathrm{Na} \mathrm{VO}_{4}$ ). The kidney cell lysates were centrifuged at $10,000 \times \mathrm{g}$ for $5 \mathrm{~min}$ at $4^{\circ} \mathrm{C}$. The supernatant was used immediately or stored at $-80^{\circ} \mathrm{C}$. Protein concentrations were determined using a Bradford assay and $4 \mathrm{mg} / \mathrm{ml}$ BSA (Applygen Technologies, Inc.; cat. no. P1512) was used as the protein standard. Proteins ( $28 \mu \mathrm{g} /$ lane) were loaded on a SDS-gel, resolved using 10\% SDS-PAGE and transferred to a PVDF membrane. Membranes were blocked in 3\% BSA/PBS at room temperature for $90 \mathrm{~min}$. PVDF membranes were subsequently incubated overnight at $4^{\circ} \mathrm{C}$ with different primary antibodies at dilutions (anti-p-EGFR 1:1,000, anti-EGFR 1:1,000, anti-p-Cerb-B2 1:1,000, anti-Cerb-B2 1:1,000, anti-H-Ras 1:1,500, anti-B-Raf 1:1,000, anti-Raf-1 1:1,000, anti-p-MEK-1/2 1:2,000, anti-MEK-1/2 1:2,000, anti-p-ERK 1:2,000, anti-ERK-1/2 1:2,000, anti-p-JNK 1:1,500, anti-JNK 1:1,500, anti-p-ASK 1:1,000, anti-ASK1 1:1,000, anti-p-p38 $\alpha$ 1:1,500, anti-p38 $\alpha / \beta \quad 1: 1,500$ and anti-actin $1: 2,000$, anti-p-PI3K 1:1,000, anti-PI3K 1:1,000, anti-p-AKT 1:1,000, anti-AKT 1:1,000, anti-p-mTOR 1:1,000, anti-mTOR 1:1,000, anti-p-4E-BP1 1:1,000, anti-4E-BP1 1:1,500, anti-p-p70S6k 1:1,000, anti-p70S6k 1:1,000, anti-p-MAP3K7 1:1,000, anti-MAP3K7 1:1,500, anti-p-MKK3/6 1:1,500, anti-MKK3 1:1,500, anti-p-MKK4 1:2,000 and anti-MKK4 1:2,000) in accordance with manufacturer's instructions (Santa Cruz Biotechnology, Inc. or Cell Signaling Technology, Inc.). Then, PVDF membranes were washed with TBS-Tween $(0.1 \%)$ and incubated with secondary antibodies at room temperature for $40 \mathrm{~min}$. The specific protein bands were visualized using an ECL chemiluminescence detection kit. Intensity of the protein bands was measured by densitometry and semi-quantified using Quantity One software (version 4.6.2; Bio-Rad Laboratorires, Inc.; https://www.bio-rad.com/).

Statistical analysis. The experiment was repeated three times, and experimental data were analyzed using SPSS version 16.0 (SPSS, Inc.). Data are presented as the mean \pm SEM. Comparison of homogeneity of variance amongst multiple groups was performed using a one-way ANOVA. Multiple comparisons were performed using a Tukey's post hoc test. $\mathrm{P}<0.05$ was considered to indicate a statistically significant difference. The inhibitory effect of Cur combined with GB was evaluated using Jin's modified Bürgi's formula (36). The formula was $q=E A B /(E A+E B-E A x E B)$, where $E A B$ is the inhibitory effect of drug A combined with drug $B$, and $E A$ and $\mathrm{EB}$ are the effects of drug $\mathrm{A}$ and $\mathrm{B}$, respectively. A q-value 
A

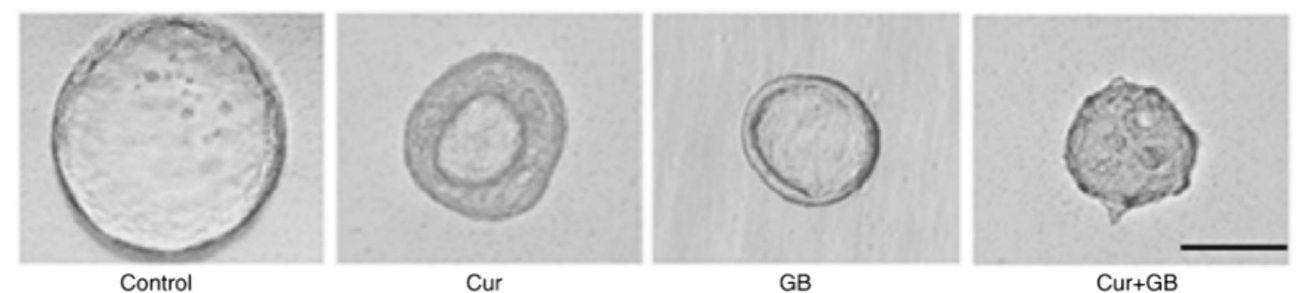

B

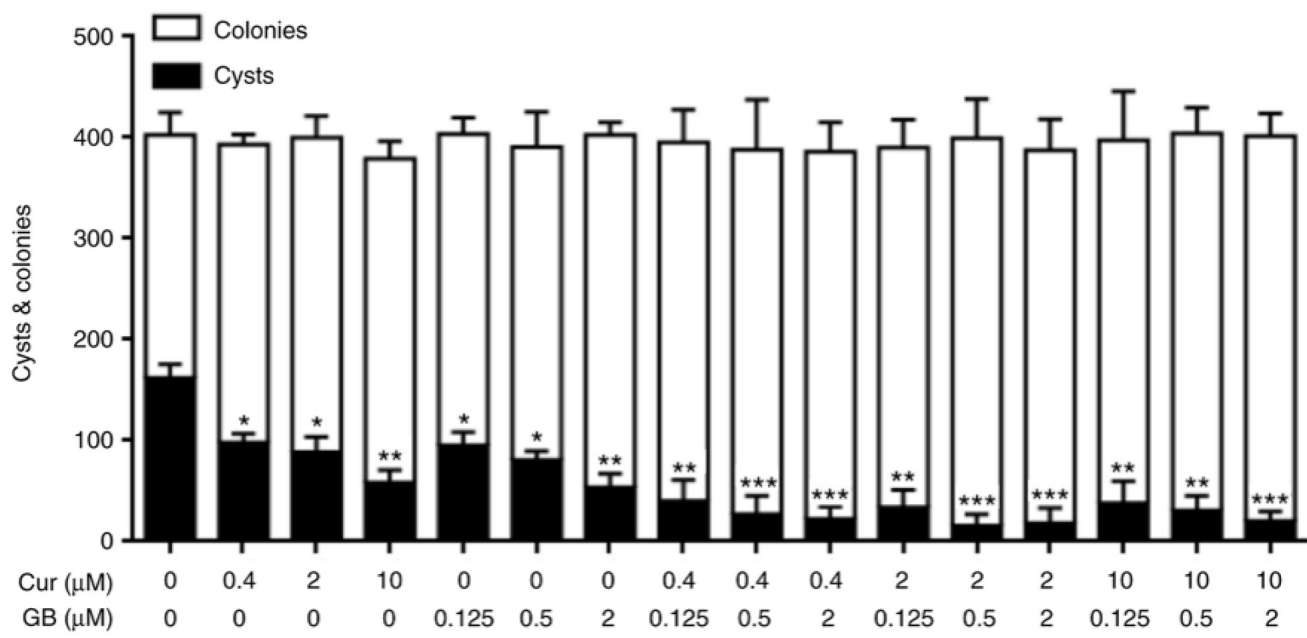

Figure 1. Combination of Cur and GB synergistically inhibits cyst formation in MDCK cyst model. (A) Representative light micrographs of MDCK cyst formation in collagen gels. Light micrographs were taken on day 6 after MDCK cell seeding in presence of FSK in collagen gels. Scale bar, $50 \mu \mathrm{m}$. Control group was treated with DMSO. Cur group was treated with $2 \mu \mathrm{M}$ Cur; GB group was treated with $0.5 \mu \mathrm{M}$ GB; Cur + GB group was treated with $2 \mu \mathrm{M} \mathrm{Cur} \mathrm{combined} \mathrm{with}$ $0.5 \mu \mathrm{M}$ GB. (B) Rate of MDCK cyst formation on day 6 after MDCK cells were cultured with $10 \mu \mathrm{M}$ FSK in the presence of the different combinations of Cur and GB. White bars show the total numbers of colonies (including cysts and non-cyst colonies). Black bars show the numbers of cysts with diameter $>50 \mu \mathrm{m}$. Data are presented as the mean $\pm \mathrm{SEM} ; \mathrm{n}=3 .{ }^{*} \mathrm{P}<0.05,{ }^{* *} \mathrm{P}<0.01$ and ${ }^{* * * *} \mathrm{P}<0.001$ vs. control $(0 \mu \mathrm{M}$ Cur $+0 \mu \mathrm{M}$ GB). (C) Inhibitory effects of Cur combined with GB on MDCK cysts. It was found that $0.4 \mu \mathrm{M} \mathrm{Cur}+0.5 \mu \mathrm{M} \mathrm{GB}, 0.4 \mu \mathrm{M}$ Cur $+2 \mu \mathrm{M}$ GB and $2 \mu \mathrm{M}$ Cur $+0.5 \mu \mathrm{M}$ GB exert a synergy effect. ${ }^{*} \mathrm{P}<0.05$ and ${ }^{* * *} \mathrm{P}<0.01$ vs. treatment of Cur alone at same concentration. Data are presented as the mean \pm SEM, $\mathrm{n}=3$. FSK, forskolin; Cur, curcumin; GB, ginkgolide B.

between 0.85-1.15 indicates that the effects of drug $\mathrm{A}$ and $\mathrm{B}$ are additive. A q-value $>1.15$ indicates that the effects of drug $\mathrm{A}$ and $\mathrm{B}$ are synergistic, while a $\mathrm{q}$-value $<0.85$ indicates that the effects of drug A and B are antagonistic (37).

\section{Results}

Cur combined with GB synergistically inhibits cyst formation and growth in the MDCK cyst model. As presented in Fig. 1A and B, the MDCK cells exposed to Cur primarily became small thick-walled cysts; however, the MDCK cells exposed to GB became small thin-walled cysts. These morphological differences suggested that Cur and GB may mediate their effects via different mechanisms. The MDCK cyst model was used to assess the inhibitory effect of Cur combined with GB cyst formation in vitro. The combination of Cur and GB significantly reduced the formation of MDCK cysts. The maximum inhibitory rate of MDCK cysts treated with a combination of $2 \mu \mathrm{M}$ Cur and $0.5 \mu \mathrm{M}$ GB was as high as $90.46 \%$, and the synergistic effect ( $\mathrm{q}>1.15$ ) was significantly greater compared with either Cur or GB alone (Fig. 1C; $\mathrm{P}<0.01)$; the maximum MDCK cyst inhibitory rate of Cur and GB was 63.82 and $66.73 \%$, respectively (Fig. 1C). The cysts formed on day 4 and were observed every 2 days from days 4 

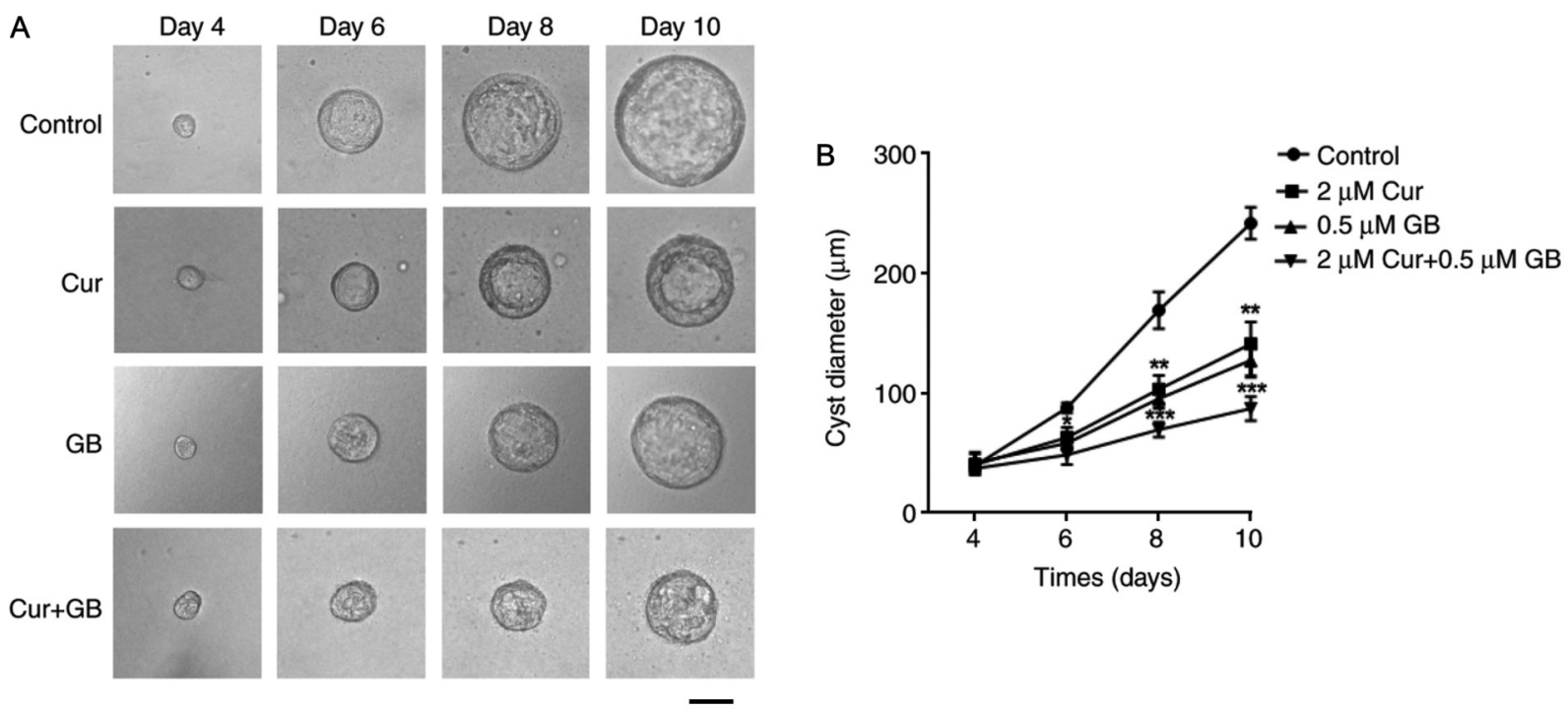

Figure 2. Combination of Cur and GB synergistically slows cyst enlargement in MDCK cyst model. (A) Representative light micrographs of MDCK cell cyst enlargement in collagen gels. Light micrographs taken at indicated days after cell seeding. MDCK cells in control group were exposed continuously to $10 \mu \mathrm{M}$ forskolin (top panel). A total of $2 \mu \mathrm{M} \mathrm{Cur} \mathrm{(second} \mathrm{panel),} 0.5 \mu \mathrm{M} \mathrm{GB}$ (third panel) and $2 \mu \mathrm{M}$ Cur combined with $0.5 \mu \mathrm{M}$ GB (bottom panel) were added from day 4 to day 10 after cell seeding in gels. Scale bar, $50 \mu \mathrm{m}$. (B) MDCK cell cyst enlargement shown as cyst diameters in different groups. Data are presented as the mean $\pm \mathrm{SEM},>30$ cysts analyzed per time point. ${ }^{*} \mathrm{P}<0.05,{ }^{* *} \mathrm{P}<0.01$ and ${ }^{* * *} \mathrm{P}<0.001$ vs. control. Cur, curcumin; GB, ginkgolide $\mathrm{B}$.

to 10 (Fig. 2A; top panel). The progressive growth of cysts was inhibited by treatment with Cur and GB alone, as well as in combination (Fig. 2B).

Cur combined with GB synergistically inhibits cyst enlargement in the PKD mouse model. The combination of Cur and GB significantly decreased renal enlargement in mice (Fig. 3A). After 10 days of treatment, the ratio of kidney weight to body weight of the PKD mice treated with Cur or GB was significantly declined compared with the PKD mice treated with DMSO + saline (Fig. 3B). The combination of Cur and GB was more effective compared with Cur in decreasing the ratio of kidney weight to body weight of the PKD mice. There was a downward tendency in the ratio of kidney weight to body weight of the PKD mice treated with Cur combined with GB, compared with GB. Hematoxylin and eosin-stained kidney sections demonstrated that the percentage of cyst area to kidney area was also decreased in PKD mice treated with Cur and/or GB (Fig. 3A and C). The combination of Cur and GB was more effective compared with Cur or GB alone in decreasing the percentage of cyst area to kidney area of the PKD mice. Although the kidney cyst expanded progressively, the BUN levels suggested that renal function in PKD mice treated with Cur and/or GB did not decrease as rapidly compared with that of the PKD mice treated with DMSO + saline (Fig. 3E). There were no differences in the ratio of kidney weight to body weight between the male and female mice in the same group (Fig. 3D). Moreover, there was no significant difference in spleen index or liver index between the PKD mice, irrespective of treatments (Fig. 3F and G).

Cur and GB decrease the activity of the EGFR/ERK1/2 signaling pathway. To further examine the mechanisms via which Cur and GB inhibited cyst formation, the activity of the EGFR/ERK1/2 signaling pathway was assessed using western blotting and immunohistochemistry on the kidneys obtained from the PKD mice (Fig. 4A and B). The expression levels of p-EGFR, p-Cerb-B2, H-Ras, B-Raf, p-MEK and p-ERK were increased in the kidneys of the PKD mice. However, the expression of Raf- 1 was decreased in the kidneys of the PKD mice. The inhibitory effect of Cur combined with GB on EGFR/ERK1/2 signaling pathway was also examined (Fig. 4C). The expression levels of p-EGFR, p-Cerb-B2, H-Ras, B-Raf, p-MEK and p-ERK were downregulated by Cur, GB and Cur combined with GB, while the expression of Raf-1 was upregulated by GB and Cur combined with GB (Fig. 4C). These results suggested that Cur combined with GB inhibited the development of renal cysts by regulating the EGFR/ERK1/2 signaling pathway.

Cur and GB downregulate the ASK1/JNK signaling pathway. To determine whether the JNK signaling pathway was involved in cyst inhibition in vivo, the expression of the ASK $1 / \mathrm{JNK}$ signaling pathway was measured via western blotting in kidneys of PKD mice treated with Cur, GB or Cur combined with GB (Fig. 5A). The expression levels of p-ASK1, p-MKK4 and p-JNK were increased in the kidneys of PKD mice, and were downregulated by Cur, GB and Cur combined with GB (Fig. 5B). Cur was more effective compared with GB in inhibiting the JNK signaling pathway. These results indicated that Cur combined with GB inhibited the development of renal cysts by regulating the ASK1/JNK signaling pathway.

$G B$ downregulates the MAP3K7/p38 signaling pathway. The expression of the MAP3K7/p38 signaling pathway was assessed via western blotting in kidneys of PKD mice treated with Cur, GB or Cur combined with GB (Fig. 6A). The expression levels of p-MAP3K7, p-MKK3 and p-p38 were increased in the kidneys of PKD mice, and were significantly downregulated by GB treatment, as well as by Cur combined with GB treatment. (Fig. 6B). There was no difference between the mice treated with GB and Cur combined with GB. Cur 
A

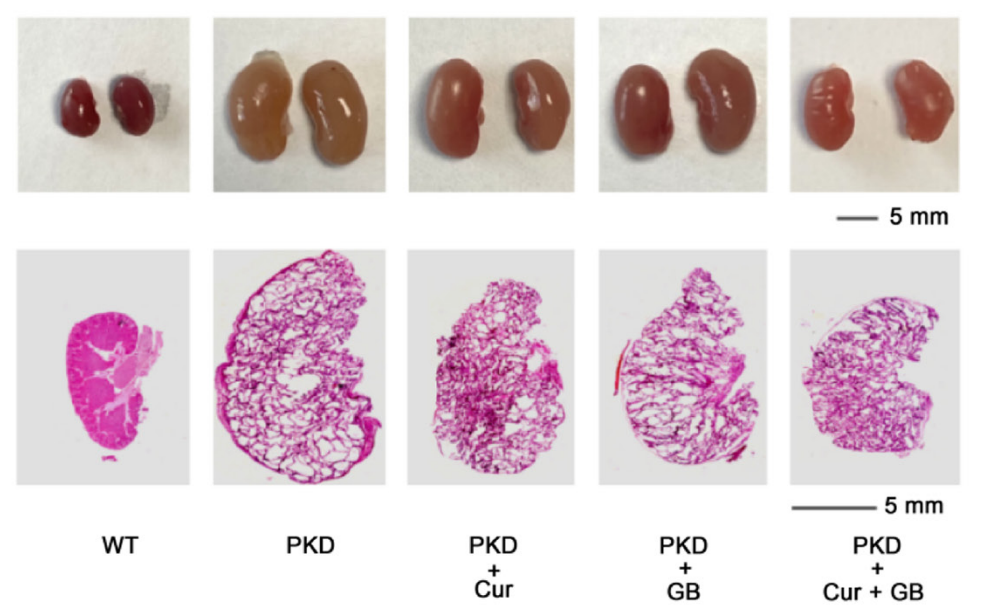

C

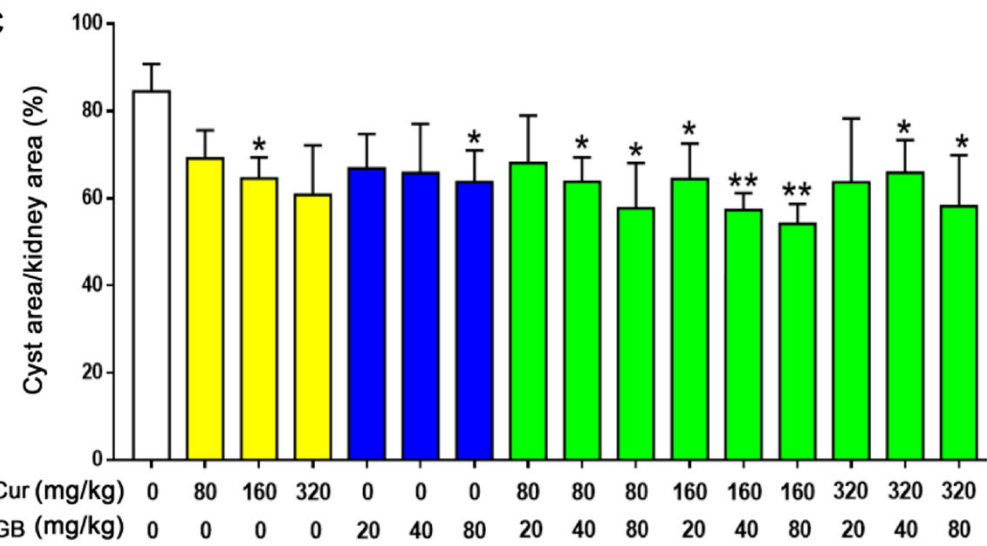

B
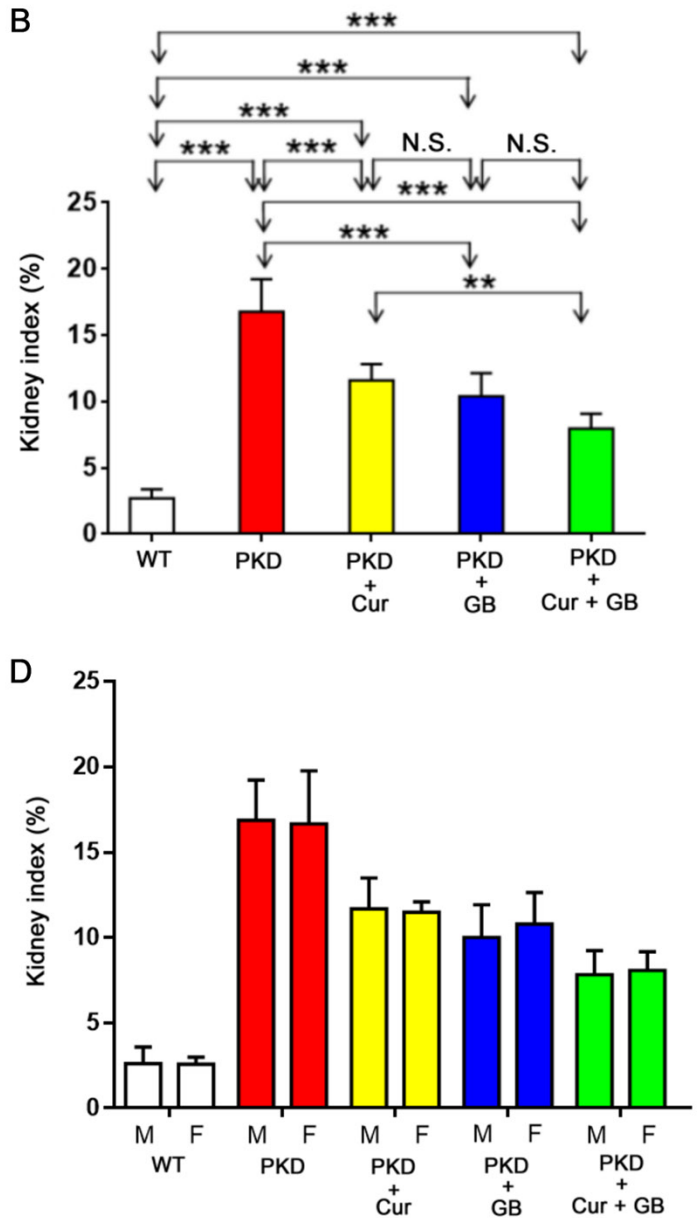
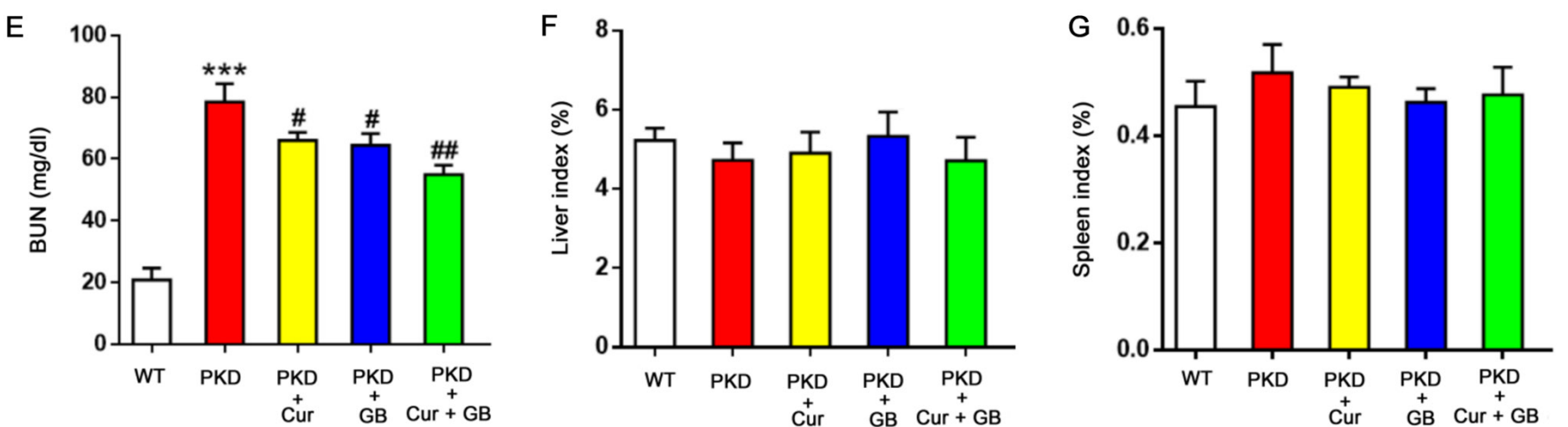

Figure 3. Combination of Cur and GB synergistically inhibits cyst enlargement in $P k d l^{F l o x /}$; Ksp-Cre mice. (A) Representative images (top panel) and hematoxylin and eosin staining images (bottom panel) of the kidney (on postnatal day 11) of WT mice, PkdI Flox/; Ksp-Cre mice treated with DMSO + saline, $160 \mathrm{mg} / \mathrm{kg}$ Cur, $80 \mathrm{mg} / \mathrm{kg} \mathrm{GB}$ and $160 \mathrm{mg} / \mathrm{kg}$ Cur combined with $80 \mathrm{mg} / \mathrm{kg} \mathrm{GB}$. (B) Kidney weight indexes of WT mice and PkdI $1^{F l o x /} ; K s p$-Cre mice treated with DMSO + saline, $160 \mathrm{mg} / \mathrm{kg}$ Cur, $80 \mathrm{mg} / \mathrm{kg} \mathrm{GB}$ and $160 \mathrm{mg} / \mathrm{kg}$ Cur combined with $80 \mathrm{mg} / \mathrm{kg}$ GB. Data are presented as the mean $\pm \mathrm{SEM}, \mathrm{n}=6 .{ }^{* *} \mathrm{P}<0.01$ and ${ }^{* * * *} \mathrm{P}<0.001$. (C) Kidney cysts were evaluated as the percentage of cyst area to kidney area in different combinations of Cur and GB. Data are presented as

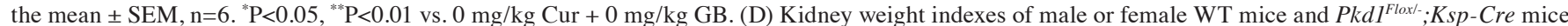
treated with DMSO + saline, $160 \mathrm{mg} / \mathrm{kg}$ Cur, $80 \mathrm{mg} / \mathrm{kg} \mathrm{GB}$ and $160 \mathrm{mg} / \mathrm{kg}$ Cur combined with $80 \mathrm{mg} / \mathrm{kg}$ GB. Data are presented as the mean \pm SEM, $\mathrm{n}=6$. (E) BUN levels in WT mice, $P k d I^{F l o x /} ; K s p$-Cre mice treated with DMSO + saline, $160 \mathrm{mg} / \mathrm{kg} \mathrm{Cur}, 80 \mathrm{mg} / \mathrm{kg} \mathrm{GB}$ and $160 \mathrm{mg} / \mathrm{kg}$ Cur combined with $80 \mathrm{mg} / \mathrm{kg}$ GB. Data are presented as the mean $\pm \mathrm{SEM}, \mathrm{n}=6 .{ }^{* * *} \mathrm{P}<0.001$ vs. WT mice; ${ }^{*} \mathrm{P}<0.05$ and ${ }^{\# \#} \mathrm{P}<0.01$ vs. PKD mice. (F) Liver weight indexes of $\mathrm{PKD}$ mice treated with or without $160 \mathrm{mg} / \mathrm{kg}$ Cur and or $80 \mathrm{mg} / \mathrm{kg} \mathrm{GB}$. Data are presented as the mean $\pm \mathrm{SEM}, \mathrm{n}=6$. (G) Spleen weight indexes of PKD mice treated with or without $160 \mathrm{mg} / \mathrm{kg}$ Cur and or $80 \mathrm{mg} / \mathrm{kg}$ GB. Data are presented as the mean \pm SEM, $\mathrm{n}=6$. WT, wild-type; N.S., no statistical significance; PKD, polycystic kidney disease; Cur, curcumin; GB, ginkgolide B; M, male; F, female; BUN, blood urea nitrogen.

failed to inhibit the MAP3K7/p38 signaling pathway (Fig. 6B). There was also no difference between the mice treated with and without Cur. These results suggested that GB inhibited the development of renal cysts by regulating the MAP3K $7 / \mathrm{p} 38$ signaling pathway.
Cur downregulates the PI3K/mTOR signaling pathway. The $\mathrm{PI} 3 \mathrm{~K} / \mathrm{mTOR}$ pathway has been reported to be associated with abnormal proliferation of cyst epithelial cells (38). In the present study, the expression levels of p-PI3K, p-AKT, p-mTOR, p-4E-BP1 (S65) and p-p70S6k were assessed using 
A

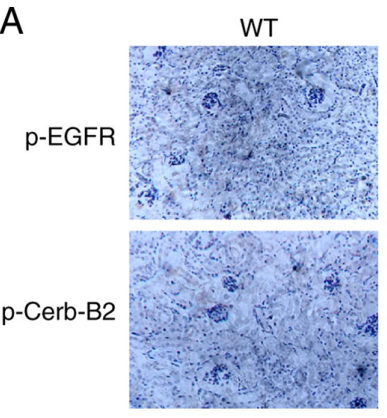

B
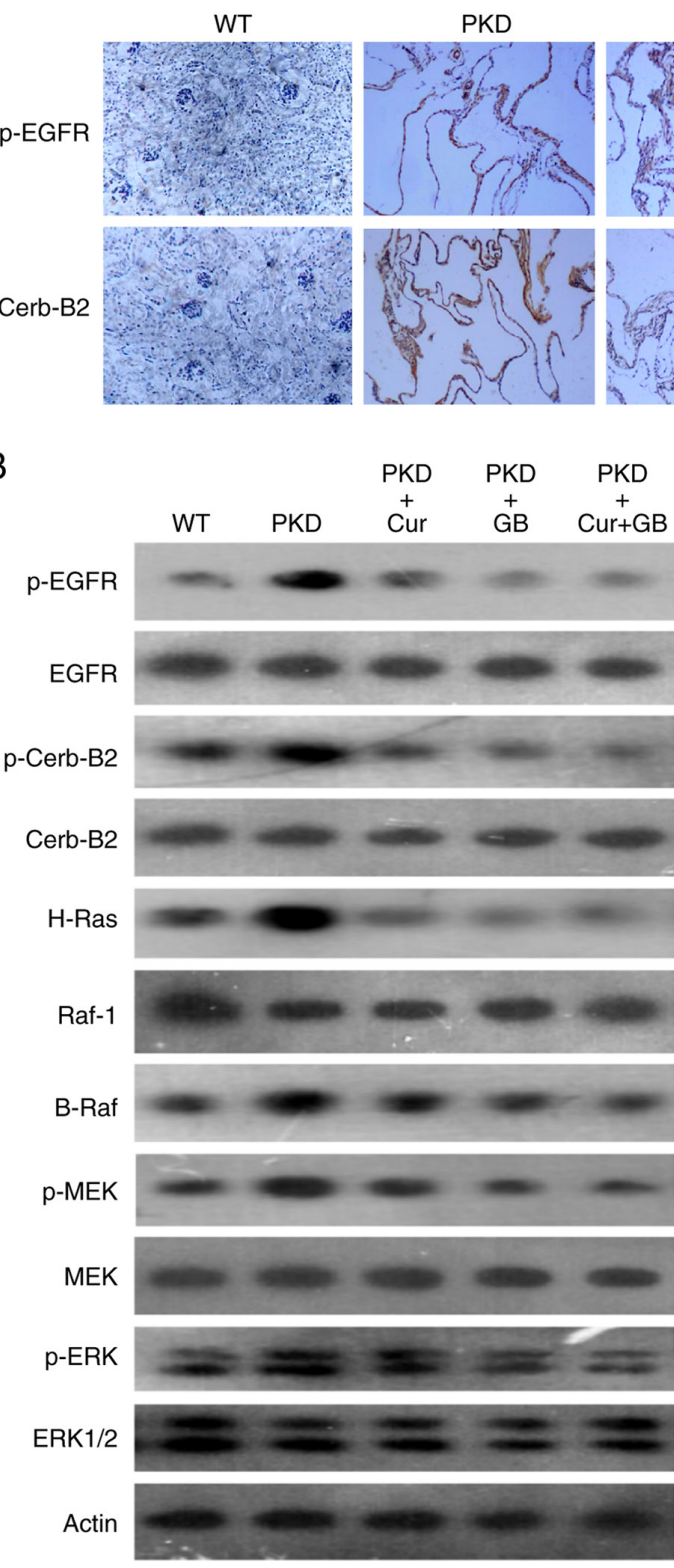

PKD+Cur

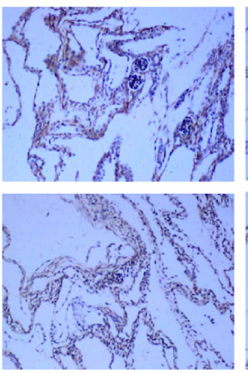

$\mathrm{C}$
$\mathrm{PKD}+\mathrm{GB} \quad \mathrm{PKD}+\mathrm{Cur}+\mathrm{GB}$
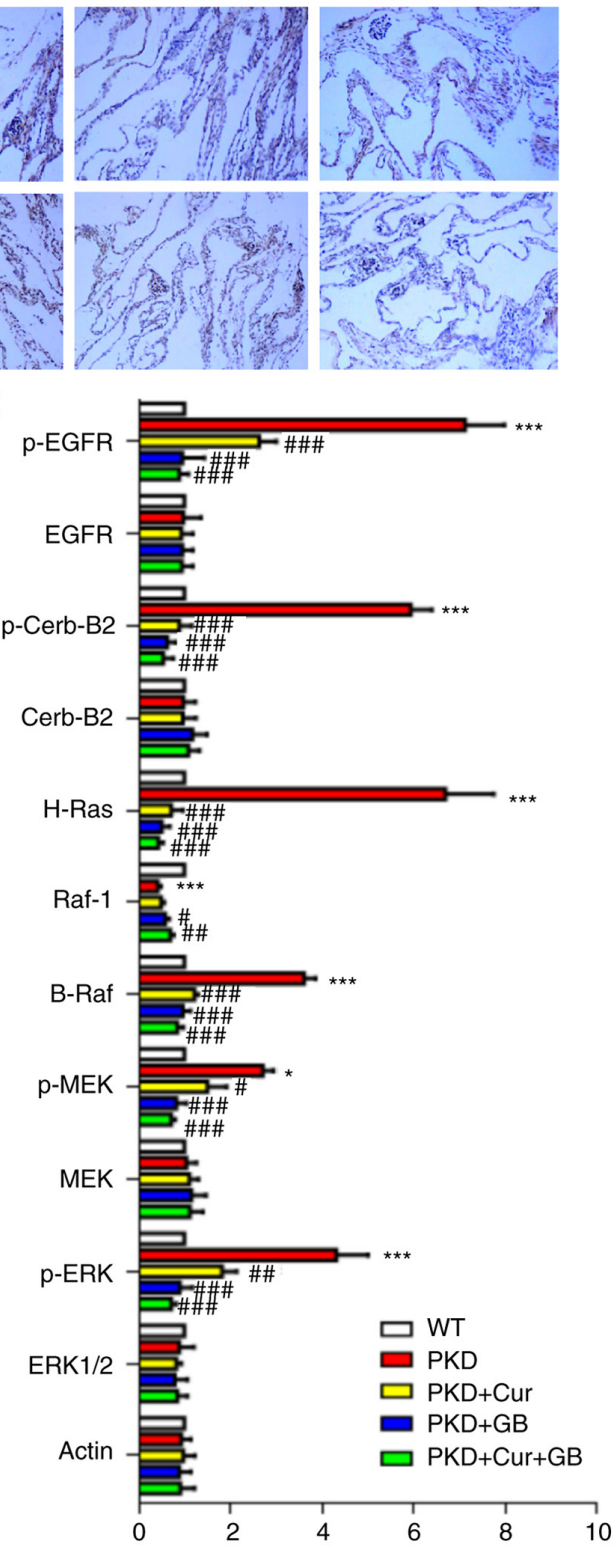

Figure 4. Cur combined with GB regulates the EGFR/ERK1/2 signaling pathway in $P k d l^{F l o x /}$; Ksp-Cre mice. (A) Representative immunohistochemistry of p-EGFR and p-Cerb-B2 in $P k d 1^{F l o x /}$; Ksp-Cre mice treated with $160 \mathrm{mg} / \mathrm{kg} \mathrm{Cur,} 80 \mathrm{mg} / \mathrm{kg} \mathrm{GB}$ and $160 \mathrm{mg} / \mathrm{kg}$ Cur combined with $80 \mathrm{mg} / \mathrm{kg} \mathrm{GB}$. Magnification, x400. (B) Representative western blotting of EGFR/ERK1/2 signaling proteins in $P k d l^{F l o x /} ; K s p$-Cre mice treated with $160 \mathrm{mg} / \mathrm{kg} \mathrm{Cur}, 80 \mathrm{mg} / \mathrm{kg} \mathrm{GB}$ and $160 \mathrm{mg} / \mathrm{kg}$ Cur combined with $80 \mathrm{mg} / \mathrm{kg} \mathrm{GB}$. (C) Semi-quantitative analysis of EGFR/ERK1/2 signaling protein expression levels in $P k d l^{F l o x /} ; K_{s p}$-Cre mice. Relative level refers to the ratio of western blotting band density in different treatment groups compared with that in WT group. Data are presented as the mean \pm SEM, $n=6$. ${ }^{*} \mathrm{P}<0.05$ and ${ }^{* * * *} \mathrm{P}<0.001$ vs. WT mice; ${ }^{*} \mathrm{P}<0.05,{ }^{\# \#} \mathrm{P}<0.01$ and ${ }^{\# \# \#} \mathrm{P}<0.001$ vs. PKD mice. WT, wild-type; PKD, polycystic kidney disease; Cur, curcumin; GB, ginkgolide B; p-, phosphorylated; Cerb-B2, human epidermal growth factor receptor 2.

western blotting on the kidney samples of PKD mice treated with Cur, GB or Cur combined with GB (Fig. 7A). The expression levels of p-PI3K, p-AKT, p-mTOR, p-4E-BP1 (S65) and p-p70S6k were increased in the kidneys of the PKD mice. However, the expression levels of p-PI3K, p-AKT, p-mTOR, p-4E-BP1 (S65) and p-p70S6k were significantly decreased by Cur. GB failed to downregulate these signaling factors (Fig. 7B). There was no synergistic effect when GB and Cur were used in combination, suggesting that Cur affected the expression levels of p-PI3K, p-AKT, p-mTOR, p-4E-BP1 (S65) and p-p70S6k alone. These results indicated that Cur inhibited the development of renal cysts by downregulating the PI3K/mTOR signaling pathway.

\section{Discussion}

Curcuma longa is an essential ingredient in numerous Southeast Asian countries, where it is frequently used in curries (39). Cur is a type of rhizome extracted from Curcuma longa (40). The estimated consumption of Curcuma longa in South Asia is 1-2 g/day or higher (41), which corresponds to $31.49-62.98 \mathrm{mg}$ Cur. However, the amount of Cur in the daily diet in South Korea is only 2.7-14.8 mg (42). Thus, the Cur consumption in some countries may not be sufficient to achieve the biological effects of Cur. Cur has several beneficial pharmacological activities (43), including anti-oxidant, anti-fibrotic and anti-angiogenic properties. 

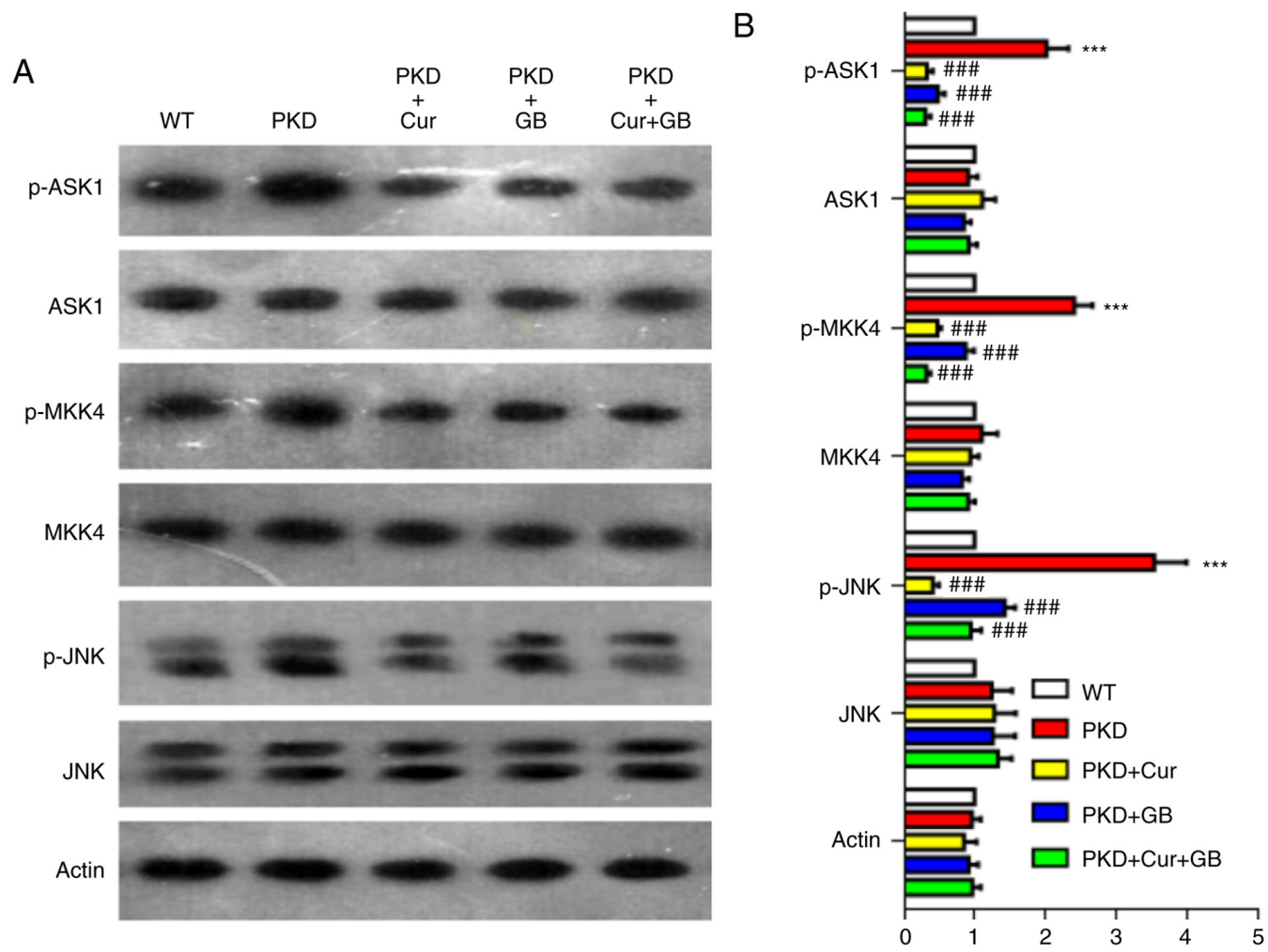

Figure 5. Cur combined with GB regulates the ASK1/JNK signaling pathway in $P k d l^{F l o x /} ; K s p$-Cre mice. (A) Representative western blotting of ASK1/JNK signaling proteins in $P k d l^{\text {Flox/ }} ;$ Ksp-Cre mice treated with $160 \mathrm{mg} / \mathrm{kg} \mathrm{Cur}, 80 \mathrm{mg} / \mathrm{kg} \mathrm{GB}$ and $160 \mathrm{mg} / \mathrm{kg}$ Cur combined with $80 \mathrm{mg} / \mathrm{kg} \mathrm{GB}$. (B) Semi-quantitative analysis of ASK1/JNK signaling protein expression in $P k d I^{F l o x /} ; K s p$-Cre mice. Relative level refers to the ratio of western blotting band density in different treatment groups compared with that in WT group. Data are presented as the mean $\pm \mathrm{SEM}, \mathrm{n}=6{ }^{* * * *} \mathrm{P}<0.001$ vs. WT mice; ${ }^{\# \# *} \mathrm{P}<0.001$ vs. PKD mice. WT, wild-type; PKD, polycystic kidney disease; Cur, curcumin; GB, ginkgolide B; p-, phosphorylated; ASK1, activator of S phase kinase; MKK, mitogen-activated protein kinase kinase.
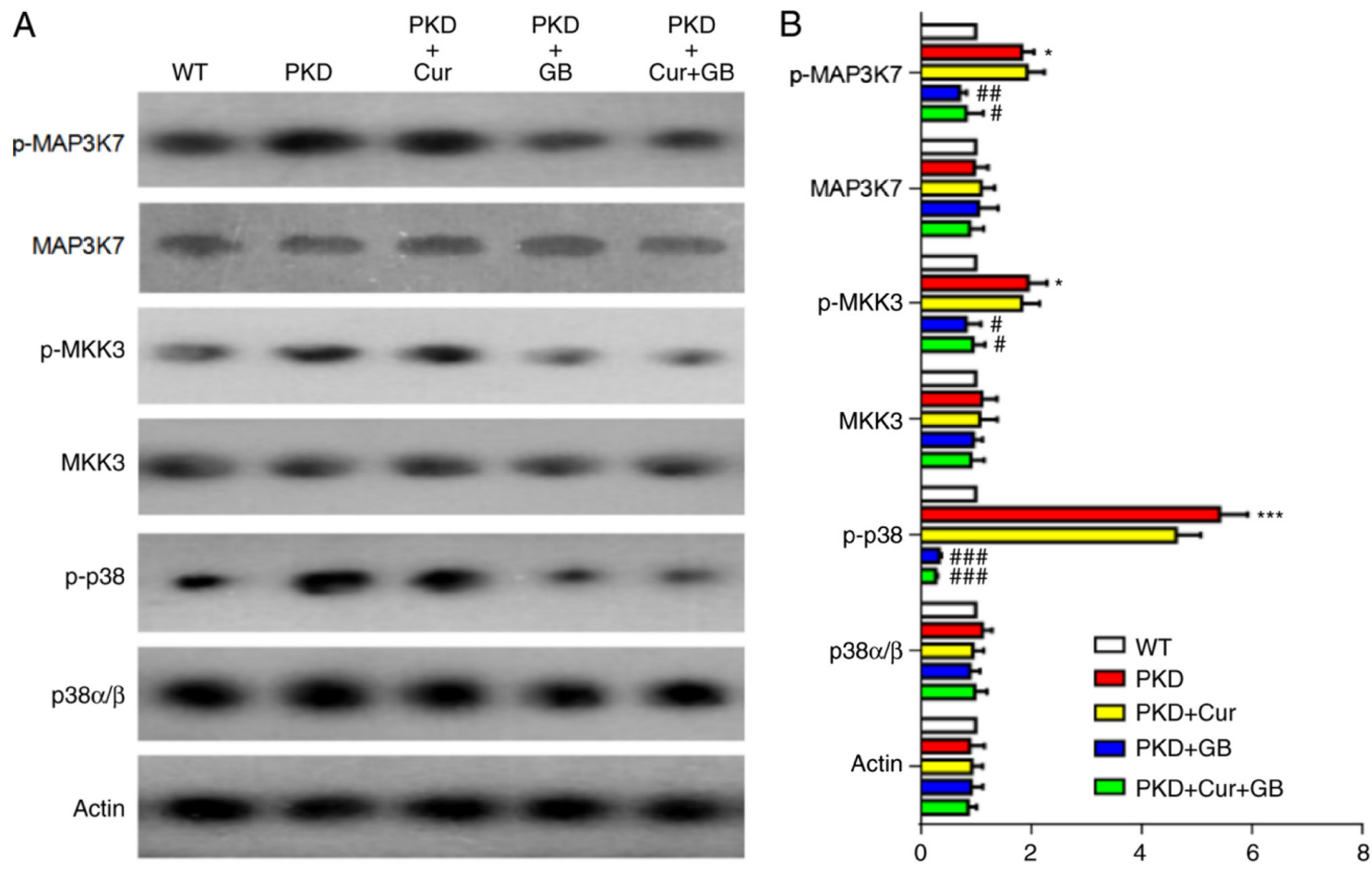

Figure 6. Cur combined with GB regulates the MAP3K7/p38 signaling pathway in $P k d l^{F l o x /}$; Ksp-Cre mice. (A) Representative western blotting of MAP3K7/p38 signaling proteins in $P k d I^{F l o x /} ; K s p$-Cre mice treated with $160 \mathrm{mg} / \mathrm{kg} \mathrm{Cur}, 80 \mathrm{mg} / \mathrm{kg} \mathrm{GB}$ and $160 \mathrm{mg} / \mathrm{kg} \mathrm{Cur} \mathrm{combined} \mathrm{with} 80 \mathrm{mg} / \mathrm{kg} \mathrm{GB}$.

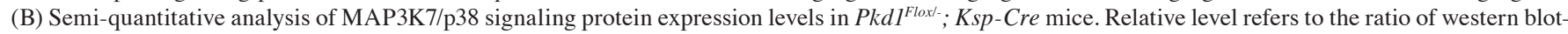
ting band density in different treatment groups compared with that in WT group. Data are presented as the mean \pm SEM, $n=6$. ${ }^{*} \mathrm{P}<0.05$ and ${ }^{* * * *} \mathrm{P}<0.001 \mathrm{vs}$. WT mice; ${ }^{P} \mathrm{P}<0.05,{ }^{\# \#} \mathrm{P}<0.001$ and ${ }^{\# \# \#} \mathrm{P}<0.001$ vs. PKD mice. WT, wild-type; PKD, polycystic kidney disease; Cur, curcumin; GB, ginkgolide B; p-, phosphorylated; MAP3K7, mitogen-activated protein kinase kinase kinase 7; MKK, mitogen-activated protein kinase kinase. 

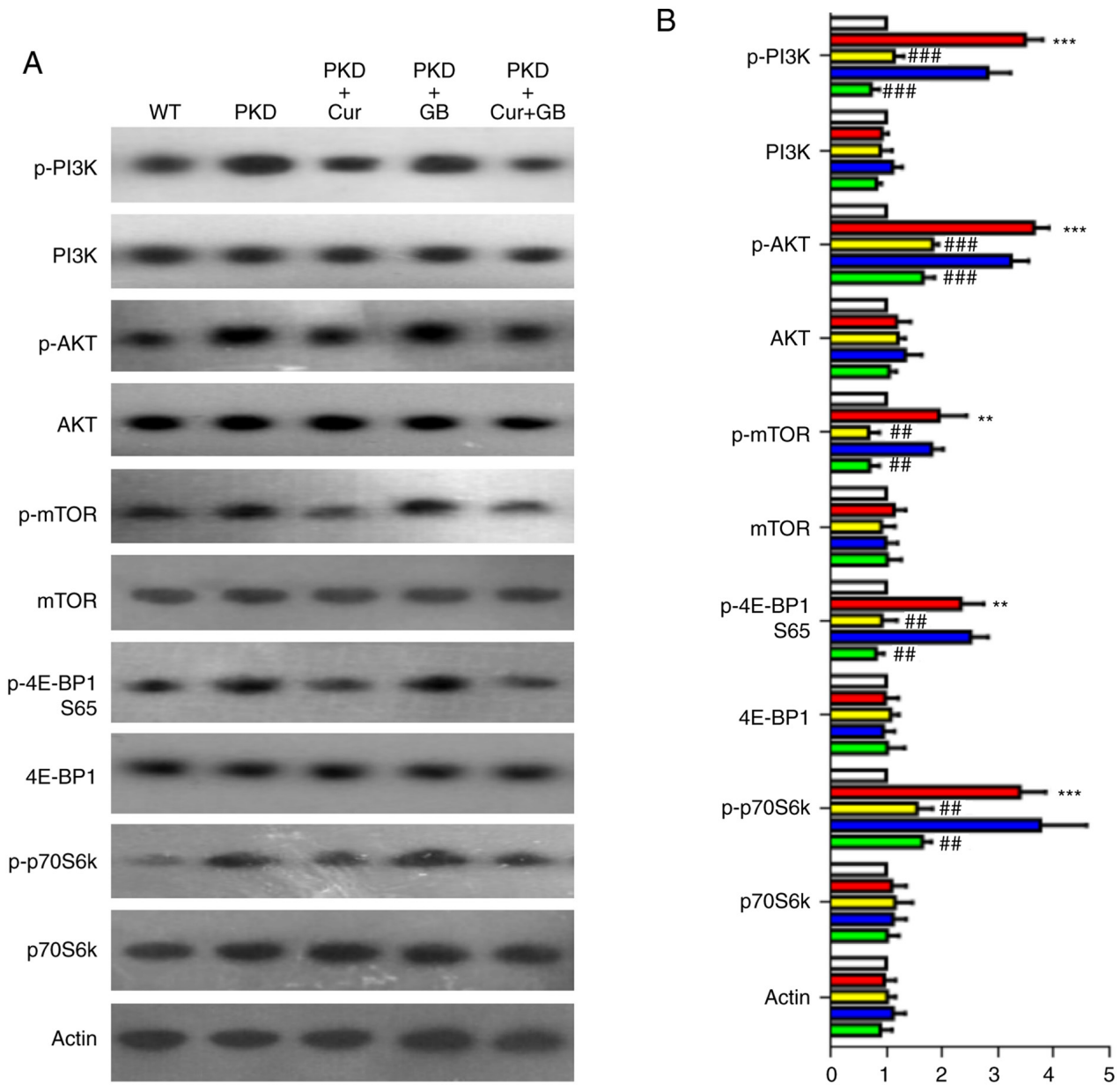

Figure 7. Cur combined with GB regulates the PI3K/mTOR signaling pathway in $P k d 1^{F l o x /}$; Ksp-Cre mice. (A) Representative western blotting of the $\mathrm{PI} 3 \mathrm{~K} / \mathrm{mTOR}$ signaling proteins in $P k d I^{F l o x /} ; K s p$-Cre mice treated with $160 \mathrm{mg} / \mathrm{kg}$ Cur, $80 \mathrm{mg} / \mathrm{kg}$ GB and $160 \mathrm{mg} / \mathrm{kg}$ Cur combined with $80 \mathrm{mg} / \mathrm{kg}$ GB (B) Semi-quantitative analysis of PI3K/mTOR signaling protein expression levels in $P k d I^{F l o x /} ; K s p$-Cre mice. Relative level refers to the ratio of western blotting band density in different treatment groups compared with that in WT group. Data are presented as the mean $\pm \mathrm{SEM}, \mathrm{n}=6 .{ }^{* *} \mathrm{P}<0.01$ and ${ }^{* * * *} \mathrm{P}<0.001 \mathrm{vs}$. WT mice; ${ }^{\# \#} \mathrm{P}<0.01$ and ${ }^{\# \# \#} \mathrm{P}<0.001$ vs. PKD mice. WT, wild-type; PKD, polycystic kidney disease; Cur, curcumin; GB, ginkgolide B; p-, phosphorylated; 4E-BP1, eukaryotic translation initiation factor 4E binding protein 1; p70S6K, p70S6 kinase.

Our previous study reported that Cur inhibited cyst development in an MDCK cyst model and embryonic kidney cyst model by downregulating the activity of the ERK signaling pathway (15).

Ginkgo is one of the oldest plants on earth, and it is colloquially referred to as a living fossil plant (44). GB is a type of terpene lactone compound extracted from GB (45). GB has several potential beneficial properties, including antiplatelet, anti-inflammatory and neuroprotective effects (46). Our previous study revealed GB also inhibited cyst growth in vivo and in vitro (17). The mechanism via which GB inhibits cyst formation is associated with the ERK signaling pathway (17).

To improve cyst inhibition, the combined effect of Cur and GB was assessed in the present study using a MDCK cyst model and $P k d 1^{\text {Flox/- }}$; Ksp-Cre mice. The combined effect of Cur and GB on cyst inhibition was greater compared with that of either compound alone, both in vitro and in vivo. The MDCK cells exposed to Cur primarily became small thick-walled cysts, whereas the MDCK cells treated with GB primarily became small thin-walled cysts. Therefore, it was hypothesized that Cur combined with GB may be more effective compared with Cur or GB alone in inhibiting cyst formation. MDCK cells treated with Cur combined with GB often formed cell colonies, and the inhibition of MDCK cyst formation rate of Cur combined with GB was $90.46 \%$. The combination of Cur and GB significantly decreased renal enlargement, but had no effect on the weight of the liver and spleen in the $P k d 1^{\text {Flox/- }}$; Ksp-Cre mice. The maximum dose of Cur in the treatment of PKD mice in the present study was $320 \mathrm{mg} / \mathrm{kg}$, which is relatively large. The United States Food and Drug Administration has approved Cur as 'Generally Recognized As Safe' (47). One study (41) revealed that rats treated with $3,500 \mathrm{mg} / \mathrm{kg}$ Cur per day for 90 days did not show any adverse effect. The human dose equivalent is $26.02 \mathrm{mg} / \mathrm{kg}$, which is determined by dividing the mouse dose $(320 \mathrm{mg} / \mathrm{kg})$ by the conversion factor for the species (that of mice is 12.3) according to previous study (48). Though the doses used in vivo cannot be reached in humans via the daily diet, $500 \mathrm{mg}$ doses of Cur twice daily have been used to treat rheumatoid arthritis with fewer adverse effects in clinical trial (49).

It was hypothesized that Cur and GB may regulate their effects on cyst formation by blocking multiple signaling 
pathways. The EGFR family includes EGFR, Cerb-B2, human epidermal growth factor receptor 3 (HER3) and HER4 (50). EGFR also serves a key role in the development of PKD (51). Some studies (52-54) revealed that the overexpression of EGFR promoted the progression of PKD by increasing the proliferation of cyst epithelial cells. The inhibitors of EGFR and its downstream signaling pathway can block the excessive proliferation of cyst epithelial cells, including EGFR inhibitor (55), Raf inhibitor (56), MEK inhibitor (57), ERK inhibitor (57) and mTOR inhibitor (58). The present study found that the EGFR/ERK1/2 signaling pathway was activated in the kidneys of PKD mouse. Moreover, the current study examined the effect of Cur, GB and Cur combined with GB on the EGFR/ERK1/2 pathway by detecting the expression and/or phosphorylation levels of signaling proteins, including EGFR, Ras, Raf, MEK and ERK. The results demonstrated that the expression of B-Raf was increased, while the levels of Raf-1 were decreased in $P k d l^{F l o x /}$; Ksp-Cre mice. Thus, B-Raf and Raf-1 may be the turn-on and turn-off switches of EGFR/ERK1/2 pathway. Both Cur and GB downregulated the expression levels of EGFR and the downstream B-Raf/ERK1/2 signaling pathway, while GB upregulated the expression of Raf-1.

The MAPK signaling pathways include not only ERK1/2, but also JNK and p38-MAPK (59). The JNK signaling pathway regulates cell proliferation and apoptosis (60). It has been reported that $P k d l$ regulates the apoptosis of renal epithelial cells via JNK activation (61). In $\mathrm{PkdI}^{\mathrm{Flox} /}$; $\mathrm{Ksp}$-Cre mice, renal epithelial cells continuously proliferated due to loss of apoptosis regulated by $P k d l$, and this proliferation induces 'compensatory' apoptosis mediated by JNK in an attempt to re-establish normal renal structure (61). It was proposed that a cyst structure may be formed as a result of central area cell apoptosis mediated by JNK and surrounding area cell proliferation mediated by ERK, p38 and other signaling factors (Fig. 8). Cur and GB inhibit the overactive JNK cascade in $\mathrm{Pkdl}^{\mathrm{Flox/} /}$; $\mathrm{Ksp}$-Cre mice. Cur is more effective compared with GB in inhibiting the JNK signaling pathway, which leads to thick-walled cysts after treatment with Cur and thin-walled cysts after GB treatment. It has been reported that the activation of p38 MAPK is associated with cyst cell proliferation (62). In the present study, the expression of p-p38 was increased in the renal tissue of $P k d l^{F l o x /} ; \mathrm{Ksp}$-Cre mice. Therefore, GB may inhibit cyst cell proliferation by downregulating the p38 MAPK signaling pathway, including p-MAP3K7, p-MKK3 and p-p38 expression levels in the kidneys of $\mathrm{Pkd1} \mathrm{Flox} /^{\mathrm{F}}$; Ksp-Cre mice. Moreover, Cur failed to inhibit the MAP3K7/p38 signaling pathway.

mTOR serves an important role in the regulation of cyst cell proliferation in ADPKD (58). The present study also evaluated the effects of Cur and GB on the mTOR pathway. Unexpectedly, Cur inhibited the PI3K/mTOR pathway, including p-PI3K, p-AKT, p-mTOR, p-4E-BP1 (S65) and p-p70S6k, in the kidneys of $P k d 1^{\text {Flox/- }} ; \mathrm{Ksp}$-Cre mice. However, GB was not able to block the PI3K/mTOR pathway. The cyst surrounding cell proliferation may be regulated by EGFR/ERK1/2, p38 and mTOR (6). Cur reduced the cyst diameter by blocking EGFR/ERK1/2 and $\mathrm{PI} 3 \mathrm{~K} / \mathrm{mTOR}$ signaling pathways. Moreover, GB decreased

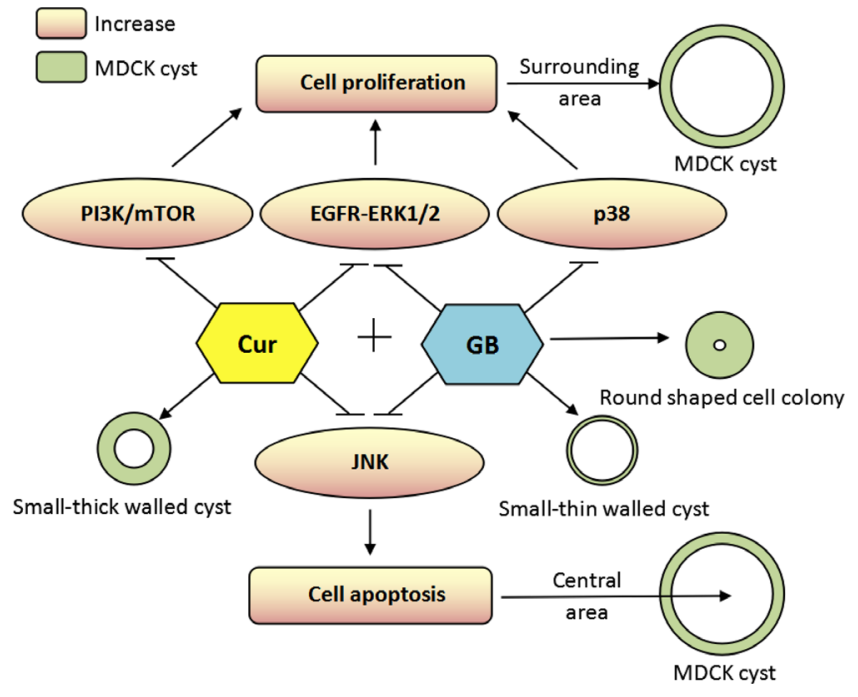

Figure 8. Tentative hypothesis for the mechanisms via which Cur and GB slows cysts development. It was proposed that the cyst structure may be formed as a result of central area cell apoptosis mediated by JNK and surrounding area cell proliferation mediated by ERFR/ERK, p38 and PI3K/mTOR. Cur is more effective compared with GB in inhibiting the JNK signaling pathway, which leads to thick-walled cysts after treatment with Cur and thin-walled cysts after GB treatment. Moreover, Cur combined with GB induces cysts to form round shaped cell colonies. Cur, curcumin; GB, ginkgolide B.

cyst diameter by downregulating EGFR/ERK1/2 and p38 signaling pathways.

However, there were several limitations in this study. First, it was not clear which signaling pathway had the largest effect on cyst formation, and the specific interactions between the identified signaling pathways were not studied. Considering that there are numerous types of combinations of Cur and GB, it is difficult to use specific inhibitors to prove their inhibition is indeed as a result of EGFR/ERK1/2, JNK and PI3K/mTOR signaling pathways. Our previous studies $(15,17)$ and other studies $(63,64)$ have confirmed that the mechanism of Cur or GB is associated with ERK1/2 and mTOR signaling pathways. Accordingly, the mechanism of Cur and GB is credible, but at present, it is complex to identify the most important relative signaling pathway. Thus, future studies will optimize the combination of Cur and GB, and use specific inhibitors to clarify the key mechanism of inhibition of cystogenesis. Secondly, average daily consumption of Cur and GB in humans may be insufficient to exert notable biological effects $(42,65)$. Considering the oral bioavailability of Cur in mice is very low, the present study administered Cur subcutaneously. Cur has no obvious adverse effect on human health (31), while GB only affects early-stage embryonic development in mice (66). Therefore, a Cur and GB combination may have risks of various interactions and side-effects, which should be further researched. Although clinical trials have demonstrated that low or similar doses of Cur or GB can be used to treat certain kidney diseases (67), there is no direct evidence showing that GB and Cur administration reached the kidney in the present study. GB is mainly excreted in urine (68), but Cur is metabolized in the liver and excreted in feces (69). Thus, the pharmacokinetics of Cur and GB will further studied. Finally, the present study did not assess any specific markers of renal fibrosis 
and cyst derivation. The rapid development of ADPKD is associated with progressive fibrosis (14), and epithelial changes lead to fibrosis in ADPKD (70). ERK and JNK/p38 MAPK, PI3K/Akt pathways are activated in fibrosis (70). In the present study, it was not possible to confirm fibrosis development and determine which cysts were derived from which tubules, as more advanced technologies and methods are required to examine these factors, in which specialist staining of fibrosis and various tubules is performed to track these over longer periods of time.

In conclusion, the present study demonstrated that Cur combined with GB inhibited cystogenesis more effectively compared with either treatment alone, both in vitro and in vivo. The molecular mechanism via which Cur and GB reduced cyst formation was found to be mediated by regulation of different signaling pathways, including EGFR/ERK1/2, JNK, p38 and mTOR. The novel combination of Cur and GB may serve as a more effective treatment for ADPKD.

\section{Acknowledgements}

The authors gratefully acknowledge the numerous contributions made by Professor Yanmei Du, Dr Dan Bao, Mrs Xiuping Xu, Mr Ligang Yang, Mrs Hui Yu, Mr Yang Liu (Ping An Healthcare and Technology Company Limited) and Dr Xiaojun Ren (Shanxi Bethune Hospital).

\section{Funding}

The present study was supported by the National Natural Science Foundation of China grant (grant no. 81302828), the Shanxi Province Science Foundation for Youths (grant no. 2013021037-3), the Taiyuan Science and Technology Fund Foundation grant (grant no. 12016911) and the Natural Science Foundation of Shanxi Province Health and Family Planning Commission (grant no. 2017093).

\section{Availability of data and materials}

The datasets used and/or analyzed during the current study are available from the corresponding author on reasonable request.

\section{Authors' contributions}

YL, JG and XY designed the study, performed the MDCK cyst model and the animal experiment, and drafted the manuscript. TL helped perform the MDCK cyst model and animal experiment. BY and AA participated in the design and coordination of the study. All authors read and approved the final version of the manuscript.

\section{Ethics approval and consent to participate}

The animal use protocol has been reviewed and approved by the Institutional Animal Care and Use Committee of Shanxi Bethune Hospital.

\section{Patient consent for publication}

Not applicable.

\section{Competing interests}

The authors declare that they have no competing interests.

\section{References}

1. Corradi V, Gastaldon F, Caprara C, Giuliani A, Martino F, Ferrari $\mathrm{F}$ and Ronco C: Predictors of rapid disease progression in autosomal dominant polycystic kidney disease. Minerva Med 108: 43-56, 2017.

2. Chebib FT, Sussman CR, Wang X, Harris PC and Torres VE: Vasopressin and disruption of calcium signalling in polycystic kidney disease. Nat Rev Nephrol 11: 451-464, 2015.

3. Harris PC and Torres VE: Genetic mechanisms and signaling pathways in autosomal dominant polycystic kidney disease. J Clin Invest 124: 2315-2324, 2014.

4. Su Q, Hu F, Ge X, Lei J, Yu S, Wang T, Zhou Q, Mei C and Shi Y: Structure of the human PKD1/PKD2 complex. Science 361: eaat9819, 2018.

5. Douguet D, Patel A and Honoré E: Structure and function of polycystins: Insights into polycystic kidney disease. Nat Rev Nephrol 15: 412-422, 2019.

6. Malekshahabi T, Khoshdel Rad N, Serra AL and Moghadasali R: Autosomal dominant polycystic kidney disease: Disrupted pathways and potential therapeutic interventions. J Cell Physiol 234: 12451-12470, 2019.

7. Gattone VH, Chen NX, Sinders RM, Seifert MF, Duan D, Martin D, Henley C and Moe SM: Calcimimetic inhibits late-stage cyst growth in ADPKD. J Am Soc Nephrol 20: $1527-1532,2009$

8. Torres VE: Cyclic AMP, at the hub of the cystic cycle. Kidney Int 66: 1283-1285, 2004.

9. Calvet JP: Strategies to inhibit cyst formation in ADPKD. Clin J Am Soc Nephrol 3: 1205-1211, 2008.

10. Shibazaki S, Yu Z, Nishio S, Tian X, Thomson RB, Mitobe M, Louvi A, Velazquez H, Ishibe S, Cantley LG, et al: Cyst formation and activation of the extracellular regulated kinase pathway after kidney specific inactivation of Pkd1. Hum Mol Genet 17: 1505-1516, 2008.

11. Pandey P, Brors B, Srivastava PK, Bott A, Boehn SNE, Groene HJ and Gretz N: Microarray-based approach identifies microRNAs and their target functional patterns in polycystic kidney disease. BMC Genomics 9: 624, 2008.

12. Yang B, Sonawane ND, Zhao D, Somlo S and Verkman AS: Small-molecule CFTR inhibitors slow cyst growth in polycystic kidney disease. J Am Soc Nephrol 19: 1300-1310, 2008.

13. He J, Zhou H, Meng J, Zhang S, Wang S, Shao G, Jin W, Geng X, Zhu S and Yang B: Cardamonin retards progression of autosomal dominant polycystic kidney disease via inhibiting renal cyst growth and interstitial fibrosis. Pharmacol Res 155: 104751, 2020.

14. Raman A, Reif GA, Dai Y, Khanna A, Li X, Astleford L, Parnell SC, Calvet JP and Wallace DP: Integrin-linked kinase signaling promotes cyst growth and fibrosis in polycystic kidney disease. J Am Soc Nephrol 28: 2708-2719, 2017.

15. Gao J, Zhou H, Lei T, Zhou L, Li W, Li X and Yang B: Curcumin inhibits renal cyst formation and enlargement in vitro by regulating intracellular signaling pathways. Eur J Pharmacol 654: 92-99, 2011.

16. Higashihara E, Nutahara K, Okegawa T, Tanbo M, Mori H, Miyazaki I, Nitatori T and Kobayashi K: Safety study of somatostatin analogue octreotide for autosomal dominant polycystic kidney disease in Japan. Clin Exp Nephrol 19: 746-752, 2015.

17. Zhou H, Gao J, Zhou L, Li X, Li W, Li X, Xia Y and Yang B: Ginkgolide B inhibits renal cyst development in in vitro and in vivo cyst models. Am J Physiol Renal Physiol 302: F1234-F1242, 2012.

18. Torres VE, Chapman AB, Devuyst O, Gansevoort RT, Perrone RD, Koch G, Ouyang J, McQuade RD, Blais JD, Czerwiec FS, et al: Tolvaptan in later-stage autosomal dominant polycystic kidney disease. N Engl J Med 377: 1930-1942, 2017.

19. Reif GA, Yamaguchi T, Nivens E, Fujiki H, Pinto CS and Wallace DP: Tolvaptan inhibits ERK-dependent cell proliferation, Cl-secretion, and in vitro cyst growth of human ADPKD cells stimulated by vasopressin. Am J Physiol Renal Physiol 301: F1005-F1013, 2011. 
20. Tesar V, Ciechanowski K, Pei Y, Barash I, Shannon M, Li R, Williams JH, Levisetti M, Arkin S and Serra A: Bosutinib versus placebo for autosomal dominant polycystic kidney disease. J Am Soc Nephrol 28: 3404-3413, 2017.

21. Li A, Xu Y, Fan S, Meng J, Shen X, Xiao Q, Li Y, Zhang L, Zhang $\mathrm{X}, \mathrm{Wu} \mathrm{G}$, et al: Canonical Wnt inhibitors ameliorate cystogenesis in a mouse ortholog of human ADPKD. JCI Insight 3: e95874, 2018

22. Cabrera-López C, Bullich G, Martí T, Català V, Ballarín J, Bissler JJ, Harris PC, Ars E and Torra R: Insight into response to mTOR inhibition when PKD1 and TSC2 are mutated. BMC Med Genet 16: 39, 2015.

23. Muto S, Aiba A, Saito Y, Nakao K, Nakamura K, Tomita K, Kitamura T, Kurabayashi M, Nagai R, Higashihara E, et al: Pioglitazone improves the phenotype and molecular defects of a targeted Pkd1 mutant. Hum Mol Genet 11: 1731-1742, 2002.

24. Raphael KL, Strait KA, Stricklett PK, Baird BC, Piontek K, Germino GG and Kohan DE: Effect of pioglitazone on survival and renal function in a mouse model of polycystic kidney disease. Am J Nephrol 30: 468-473, 2009.

25. Leuenroth SJ, Bencivenga N, Chahboune H, Hyder F and Crews CM: Triptolide reduces cyst formation in a neonatal to adult transition Pkd1 model of ADPKD. Nephrol Dial Transplant 25: 2187-2194, 2010.

26. Su L, Liu L, Jia Y, Lei L, Liu J, Zhu S, Zhou H, Chen R, Lu HAJ and Yang B: Ganoderma triterpenes retard renal cyst development by downregulating Ras/MAPK signaling and promoting cell differentiation. Kidney Int 92: 1404-1418, 2017.

27. Zhu Y, Teng T, Wang H, Guo H, Du L, Yang B, Yin X and Sun Y: Quercetin inhibits renal cyst growth in vitro and via parenteral injection in a polycystic kidney disease mouse model. Food Funct 9: 389-396, 2018.

28. Chebib FT, Perrone RD, Chapman AB, Dahl NK, Harris PC, Mrug M, Mustafa RA, Rastogi A, Watnick T, Yu ASL and Torres VE: A practical guide for treatment of rapidly progressive ADPKD with tolvaptan. J Am Soc Nephrol 29: 2458-2470, 2018

29. Yan FS, Sun JL, Xie WH, Shen L and Ji HF: Neuroprotective effects and mechanisms of curcumin-cu(II) and -zn(II) complexes systems and their pharmacological implications. Nutrients 10: 28, 2017.

30. Zhao NJ, Liao MJ, Wu JJ and Chu KX: Curcumin suppresses Notch1 signaling: Improvements in fatty liver and insulin resistance in rats. Mol Med Rep 17: 819-826, 2018.

31. Bandgar BP, Hote BS, Jalde SS and Gacche RN: Synthesis and biological evaluation of novel curcumin analogues as anti-inflammatory, anti-cancer and anti-oxidant agents. Med Chem Res 21: 3006-3014, 2012.

32. Adahoun MA, AlAkhras MH, Jaafar MS and Bououdina M: Enhanced anti-cancer and antimicrobial activities of curcumin nanoparticles. Artif Cells Nanomed Biotechnol 45: 98-107, 2017

33. Yu W, Cao L, Zhao Y, Xiao W and Xiao B: Comparing the role of Ginkgolide B and Ginkgolide K on cultured astrocytes exposed to oxygen?glucose deprivation. Mol Med Rep 18: 4417-4427, 2018.

34. Li R, Chen B, Wu W, Bao L, Li J and Qi R: Ginkgolide B suppresses intercellular adhesion molecule-1 expression via blocking nuclear factor-kappaB activation in human vascular endothelial cells stimulated by oxidized low-density lipoprotein. J Pharmacol Sci 110: 362-369, 2009.

35. Shu ZM, Shu XD, Li HQ, Sun Y, Shan H, Sun XY, Du RH, Lu M, Xiao M, Ding JH and Hu G: Ginkgolide B protects against ischemic stroke via modulating microglia polarization in mice. CNS Neurosci Ther 22: 729-739, 2016.

36. Zhou YY, Wang HY, Tang ZG and Ma DL: Two new formulae for evaluating the effectiveness of drug combinations and the revision of Bürgi's and Jin's modified Bürgi's formulae. Zhongguo Yao Li Xue Bao 5: 217-221, 1984 (In Chinese).

37. Pan YY, Xu SP and Wei W: Effect of combined nimesulide and adriamycin on proliferation and apoptosis in hepatocellular carcinoma cell line HepG_2. Chin Pharmacol Bull 22: 884-887, 2006.

38. Liu Y, Pejchinovski M, Wang X, Fu X, Castelletti D, Watnick TJ, Arcaro A, Siwy J, Mullen W, Mischak H and Serra AL: Dual mTOR/PI3K inhibition limits PI3K-dependent pathways activated upon mTOR inhibition in autosomal dominant polycystic kidney disease. Sci Rep 8: 5584, 2018.

39. Ng TP, Chiam P, Lee T, Chua H, Lim L and Kua EH: Curry consumption and cognitive function in the elderly. Am J Epidemiol 164: 898-906, 2006
40. Van Nong H, Hung LX, Thang PN, Chinh VD, Vu LV, Dung PT, Van Trung T and Nga PT: Fabrication and vibration characterization of curcumin extracted from turmeric (Curcuma longa) rhizomes of the northern Vietnam. Springerplus 5: 1147, 2016.

41. Basnet P and Skalko-Basnet N: Curcumin: An anti-inflammatory molecule from a curry spice on the path to cancer treatment. Molecules 6: 4567-4598, 2011.

42. Young joo K: Estimation of curcumin intake in Korea based on the Korea national health and nutrition examination survey (2008-2012). Nutr Res Pract 8: 589-594, 2014.

43. Maheshwari RK, Singh AK, Gaddipati J and Srimal RC: Multiple biological activities of curcumin: A short review. Life Sci 78: 2081-2087, 2006

44. Guan R, Zhao Y, Zhang H, Fan G, Liu X, Zhou W, Shi C, Wang J, Liu W, Liang X, et al: Draft genome of the living fossil Ginkgo biloba. Gigascience 5: 49, 2016.

45. Wang S, Ouyang B, Aa J, Geng J, Fei F, Wang P, Wang J, Peng Y, Geng T, Li Y, et al: Pharmacokinetics and tissue distribution of ginkgolide $\mathrm{A}$, ginkgolide $\mathrm{B}$, and ginkgolide $\mathrm{K}$ after intravenous infusion of ginkgo diterpene lactones in a rat model. J Pharm Biomed Anal 126: 109-116, 2016.

46. Zheng PD, Mungur R, Zhou HJ, Hassan M, Jiang SN and Zheng JS: Ginkgolide B promotes the proliferation and differentiation of neural stem cells following cerebral ischemia/reperfusion injury, both in vivo and in vitro. Neural Regen Res 13: 1204-1211, 2018.

47. Agrawal S: Curcumin and its protective and therapeutic uses. Natl J Physiol Pharm Pharmacol 6: 1-8, 2016.

48. Anroopb N and Shery J: A simple practice guide for dose conversion between animals and human. J Basic Clin Pharm 7: 27-31, 2016.

49. Chandran B and Goel A: A randomized, pilot study to assess the efficacy and safety of curcumin in patients with active rheumatoid arthritis. Phytother Res 26: 1719-1725, 2012.

50. Lyu H, Han A, Polsdofer E, Liu S and Liu B: Understanding the biology of HER3 receptor as a therapeutic target in human cancer. Acta Pharm Sin B 8: 503-510, 2018.

51. Zeng $\mathrm{F}$ and Harris RC: The ErbB receptors and their ligands in PKD, an overview. Curr Signal Trans Ther 5: 170-180, 2010.

52. Zheleznova NN, Wilson PD and Staruschenko A: Epidermal growth factor-mediated proliferation and sodium transport in normal and PKD epithelial cells. Biochim Biophys Acta 1812: 1301-1313, 2011.

53. Wilson SJ, Amsler K, Hyink DP, Li X, Lu W, Zhou J, Burrow CR and Wilson PD: Inhibition of HER-2(neu/ErbB2) restores normal function and structure to polycystic kidney disease (PKD) epithelia. Biochim Biophys Acta 1762: 647-655, 2006.

54. Streets AJ, Magayr TA, Huang L, Vergoz L, Rossetti S, Simms RJ, Harris PC, Peters DJM and Ong ACM: Parallel microarray profiling identifies ErbB4 as a determinant of cyst growth in ADPKD and a prognostic biomarker for disease progression. Am J Physiol Renal Physiol 312: F577-F588, 2017.

55. Torres VE, Sweeney WE, Wang X, Qian Q, Harris PC, Frost P and Avner ED: EGF receptor tyrosine kinase inhibition attenuates the development of PKD in Han:SPRD rats. Kidney Int 64: 1573-1579, 2003

56. Yamaguchi T, Reif GA, Calvet JP and Wallace DP: Sorafenib inhibits cAMP-dependent ERK activation, cell proliferation, and in vitro cyst growth of human ADPKD cyst epithelial cells. Am J Physiol Renal Physiol 299: F944-F951, 2010.

57. Spirli C, Okolicsanyi S, Fiorotto R, Fabris L, Cadamuro M, LecchiS,TianX,SomloS and StrazzaboscoM:ERK1/2-dependent vascular endothelial growth factor signaling sustains cyst growth in polycystin-2 defective mice. Gastroenterology 138: 360-371. e367, 2010.

58. De Stephanis L, Bonon A, Varani K, Lanza G, Gafà R, Pinton P, Pema M, Somlo S, Boletta A and Aguiari G: Double inhibition of cAMP and mTOR signalling may potentiate the reduction of cell growth in ADPKD cells. Clin Exp Nephrol 21: 203-211, 2017.

59. Uzgare AR, Kaplan PJ and Greenberg NM: Differential expression and/or activation of P38MAPK, erk1/2, and jnk during the initiation and progression of prostate cancer. Prostate 55: 128-139, 2003

60. Hui L, Bakiri L, Mairhorfer A, Schweifer N, Haslinger C, Kenner L, Komnenovic V, Scheuch H, Beug H and Wagner EF: p38alpha suppresses normal and cancer cell proliferation by antagonizing the JNK-c-Jun pathway. Nat Genet 39: 741-749, 2007.

61. Nishio S, Hatano M, Nagata M, Horie S, Koike T, Tokuhisa T and Mochizuki T: Pkd1 regulates immortalized proliferation of renal tubular epithelial cells through p53 induction and JNK activation. J Clin Invest 115: 910-918, 2005. 
62. Liu Y, Dai B, Xu C, Fu L, Hua Z and Mei C: Rosiglitazone inhibits transforming growth factor- $\beta 1$ mediated fibrogenesis in ADPKD cyst-lining epithelial cells. PLoS One 6: e28915, 2011.

63. Leonhard WN, Der Wal AV, Novalic Z, Kunnen SJ, Gansevoort RT, Breuning MH, Heer ED and Peters DJ: Curcumin inhibits cystogenesis by simultaneous interference of multiple signaling pathways: In vivo evidence from a Pkd1-deletion model. Am J Physiol Renal Physiol 300: F1193-F1202, 2011.

64. Aguiari G, Catizone L and Senno LD: Multidrug therapy for polycystic kidney disease: A review and perspective. Am J Nephrol 37: 175-182, 2013.

65. Lieberman HR, Kellogg MD, Fulgoni VL III and Agarwal S: Moderate doses of commercial preparations of Ginkgo biloba do not alter markers of liver function but moderate alcohol intake does: A new approach to identify and quantify biomarkers of 'adverse effects' of dietary supplements. Regul Toxicol Pharmacol 84: 45-53, 2017.

66. Shiao N and Chan W: Injury effects of ginkgolide B on maturation of mouse oocytes, fertilization, and fetal development in vitro and in vivo. Toxicol Lett 188: 63-69, 2009.
67. Hu Y, Mou L, Yang F, Tu H and Lin W: Curcumin attenuates cyclosporine Ainduced renal fibrosis by inhibiting hypermethylation of the klotho promoter. Mol Med Rep 14: 3229-3236, 2016.

68. Chen W, Liang Y, Xie L, Lu T, Liu X and Wang G: Pharmacokintics of the ginkgo bfollowing intravenous administration of ginkgo B emulsion in rats. Biol Pharm Bull 30: 1-5, 2007.

69. Fadus MC, Lau C, Bikhchandani J and Lynch HT: Curcumin: An age-old anti-inflammatory and anti-neoplastic agent. J Tradit Complement Med 7: 339-346, 2016.

70. Norman JT: Fibrosis and progression of autosomal dominant polycystic kidney disease (ADPKD). Biochim Biophys Acta 1812: 1327-1336, 2011.

This work is licensed under a Creative Commons Attribution-NonCommercial-NoDerivatives 4.0 International (CC BY-NC-ND 4.0) License. 